\title{
Adopting General Rules to Regulate Writer with Traditional Justice in Organizing the E-Certification Body in Contemporary Iraqi Legislation
}

\author{
Abdulbasit Jasim Mohammed*, Sarah Husham Abdulhameed \\ Department of Law, College of Law and Political Sciences, University of Anbar, Iraq \\ * sosonet1998@gmail.com
}

KEYWORDS: $\quad$ Iraqi Legislation, Civil Law, General Rules, Notary Public, Electronic Certification.

Crossref doi https://doi.org/10.51345/.v32i2.340.g227

\begin{abstract}
:
The legal and legal necessity in electronic and third-party legal transactions dictates, and keeps abreast of modern developments in this field, The Iraqi legislature, according to the Electronic Signature and Electronic Transactions Law No. (78) Of 2012, created the electronic authentication body, and set out the conditions for its establishment, scope of work, terms of reference and mechanisms for carrying out its activities, to be -from a functional point of view -an extension of the writer with traditional justice, organized under the provisions of the Notary Book Law No. (23) for the year 1998, However, the texts regulating the work of the first are not at the level of the legislative organization of the work of the second, which necessitates researching the extent of the success of the adaptation of the general rules regulating the writer with traditional justice, in completing the aspects of organizing the electronic documentation body in contemporary Iraqi legislation, to ensure the achievement of the goal for which this body was established, The study showed the possibility of adapting texts related to the substantive aspect, which do not contradict the default nature of the documentation side, and the impossibility of this with regard to the functional aspect, related to the nature and entity of each of them.
\end{abstract}


مدى نجاح تطويع القواعد العامة المنظمة للكاتب بالعدل التقليدي في تنظيم جهة التوثيق الإلكتروبي في التشريع العراقي المعاصر

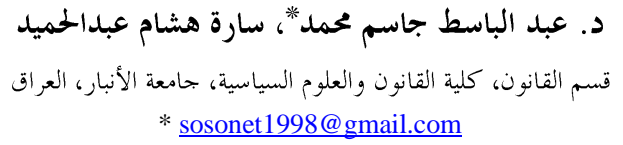

Crossref doi https://doi.org/10.51345/.v32i2.340.g227

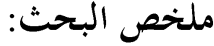

تقتضي الضرورة التقنية والقانونية في التعاملات الإلكترونية وجود طرف ثالث محايد وموثوق يتوسط بين الأطراف المتعاقدة

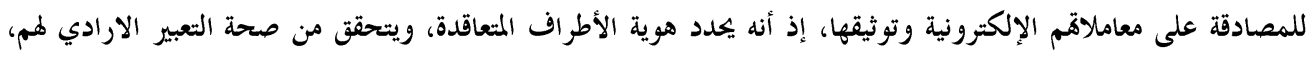
ويصادق/ يوثق التصرف القانولي الصادر عنهم، أو الجحاري على يديه طبقاً للأوضاع القانونية المقررة، ومواكبة للتطورات العصرية في هذ الميدان، فقد استحدث المشرع العراقي، بموجب قانون التوقيع الإلكترولي والمعاملات الإلكترونية رقم (78) لسنة 2012، جهة التوثيق الالكترولي، وبين شروط إنشائها ونطاق عملها واختصاصاتا وآليات ممارستها أنشطتها، لتكون من الناحية الوظيفية- امتداداً للكاتب بالعدل التقليدي، المنظمّ بموجب أحكام قانون الكتاب العدول رقم (23) لسنة 1998،

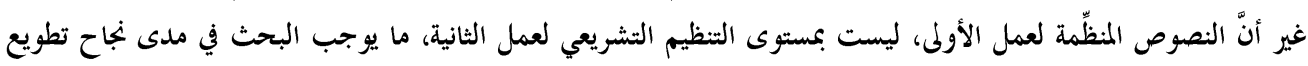
القواعد العامة المنظّمة للكاتب بالعدل التقليدي، في استكمال جوانب تنظيم جهة التوثيق الالكترولي في التشريع العراقي المعاصر، لضمان تحقيق الهدف الذي تمّ من أجله إنشاء هذه الجهة، وقد أظهرت الدراسة إمكانية تطويع النصوص المتعلقة بالجانب الموضوعي، والتي لا تتعارض مع الطبيعة الافتراضية لجهة التوثيق، وعدم إمكانية ذلك بالنسبة للجانب الوظيفي، المتعلق بطبيعة وكينونة كل منهما.

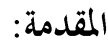

تستدعي الضرورة التقنية والقانونية في المعاملات الالكترونية وجود طرف ثالث، محايد، موثوق، يتوسط الاطراف المتعاقدة لتوثيق تعاملاكم، لما تؤديه الثقة والامان من ازدهار التعاملات الالكترونية، ومسايرة الابحاه العالمي نخو مباشرة التصرفات القانونية والمهنية عند بعد، ولاسيما عقب جائحة (كوفيد-19)(1)، ما يستلزم وجود طرف ثالث، يمثل حلقة وصل (وسيطاً) بين طرفي التصرف القانوفي محل التصديق أو التوثيق، يطلق عليه (جهة التصديق والتوثيق الالكتروني)، أو (الكاتب بالعدل الالكتروني)، يتولى مهمة 
تحديد هوية الاطراف المتعاقدة، والتحقق من صحة صدور التعبير الارادي عنهم، ونسبة كل تعبير إلى من

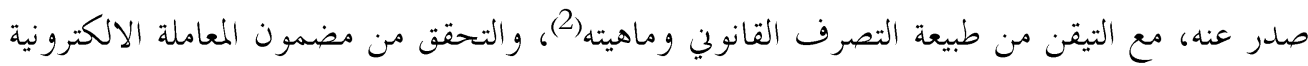

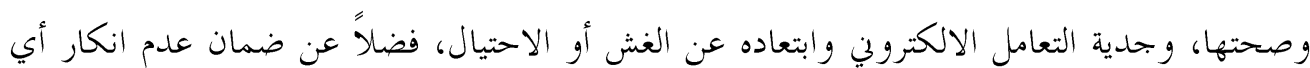

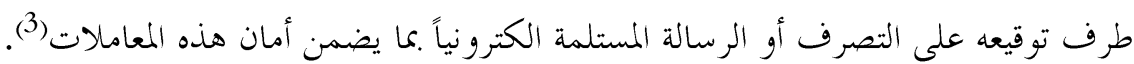

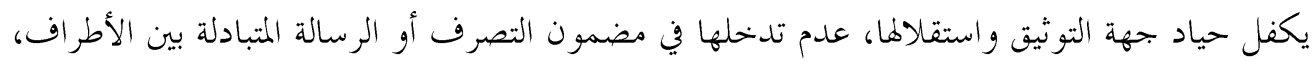
ما يعود بالنفع على نظام الاثبات وفاعليته عموماً، ويتم ذلك بطريقة توثيق التوقيع الالكتروبي عبر نوعين

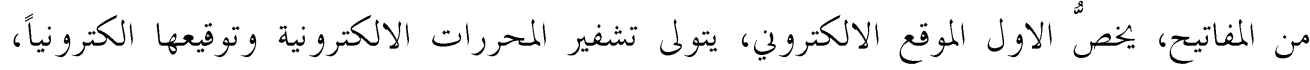

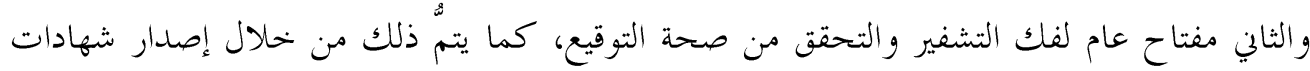

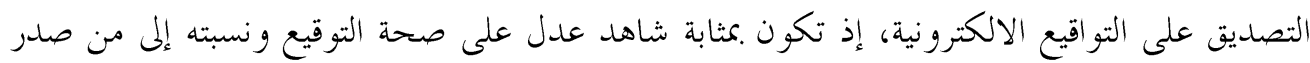

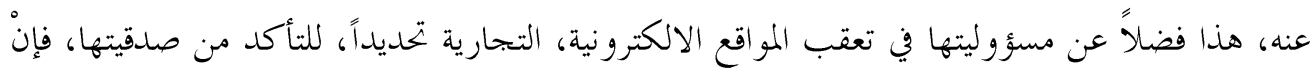

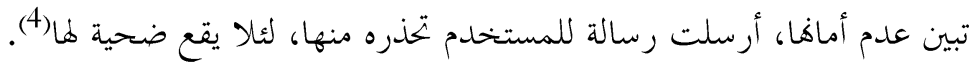

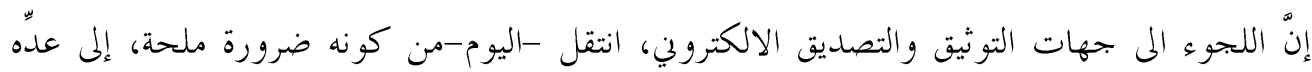

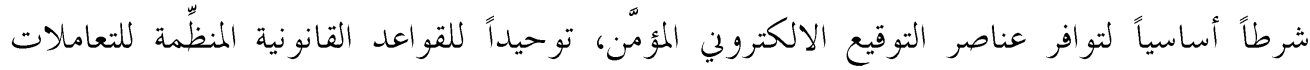

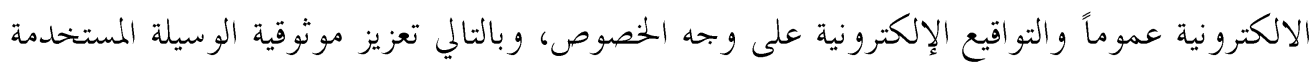

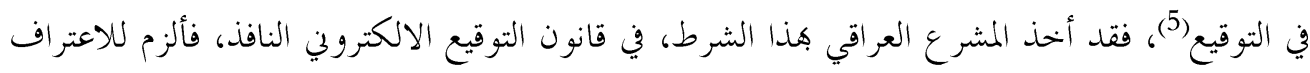

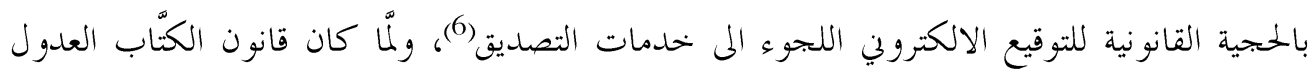

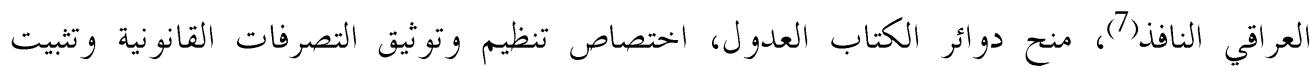

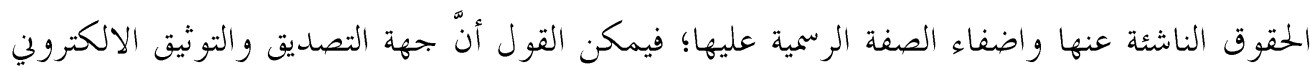

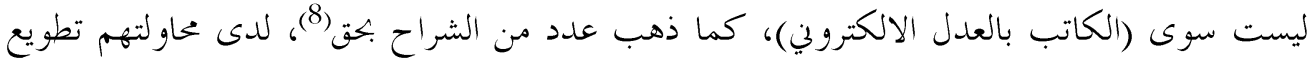
القواعد العامة المنظمة لعمل دوائر الكتاب العدول، للانطباق على جهات التوثيق الالكتروين، لاسيما عند افتقاد النص الخناص المنظم لبعض أحكام الأخيرة. ويذهب القضاء العراقي إلى أنّ وجوب توثيق التصرف القئ القانوني (وهو في هذه القضية وصية بإرادة

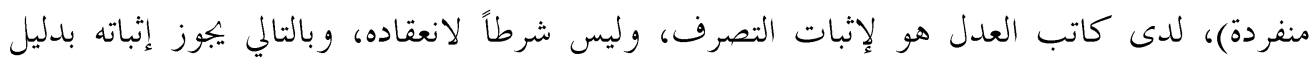

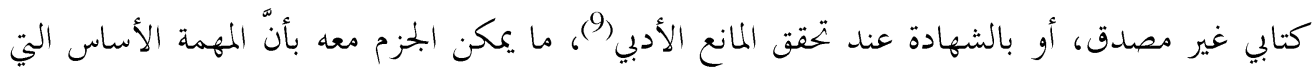

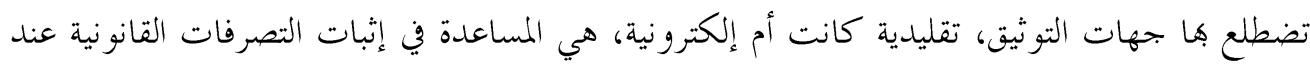

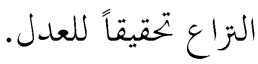


مشكلة الدراسة: تخلو القواعد القانونية المنظمة لجهة التصديق والتوثيق الالكترووني من أحكام تفصيلية دقيقة، ما يقتضي الاستعانة بالقواعد العامة المنظمة لعمل جهة التصديق والتوثيق التقليدية وهي دائرة الكاتب العدل، بقصد تقصي مدى نجاح تطويع الأخيرة، للانطباق على الأولى في التشريع العراقي

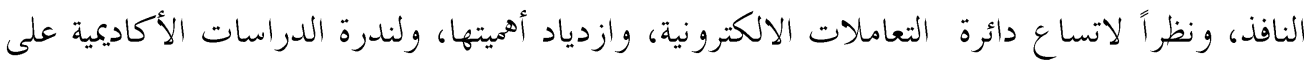

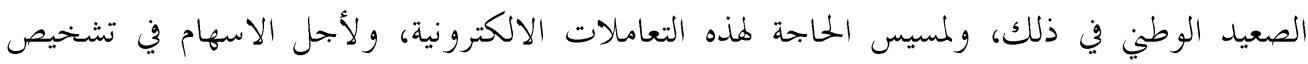
مشكلة موثوقية الطرف الاخر عبر وسائل الاتصال الفوري المعاصرة، وتقديم الحلول القانونية لها؛ كون

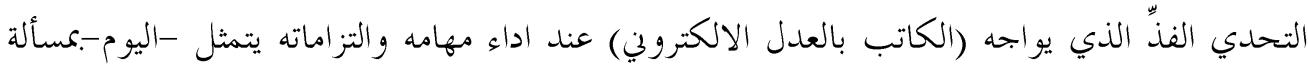
الموثوقية، من أجل ذلك كان هذا البحث. أهمية الدراسة: تتأتى من جدة وحهداثة وند وندرة ما كتب في هذا الموضوع، إذ لا يوجد سوى التزر اليسير

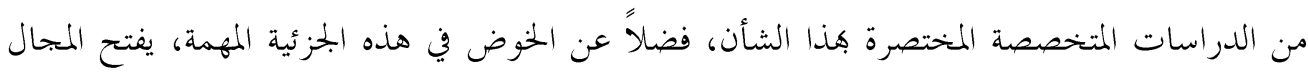

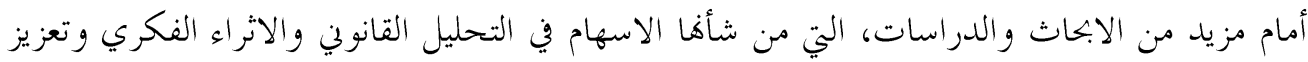

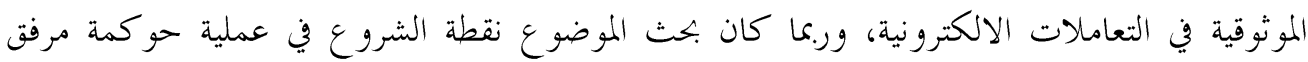
القضاء، ناهيك عن أهمية وخطورة الدور الذي تقوم به جهات التصديق والتوثيق الالكتروين، وسيلة للتثبت من شخصيات أطراف التصرف، وتحديد القواعد و النظم الملائمة التي تحكمها، تأتي هذه الدراسة محاولة للبحث عن مدى بناح تطويع القواعد القانونية المنظمة للكاتب بالعدل التقليدي، لتنظيم عمل ومسؤولية جهة التوثيق الالكتروفي في التشريع العراقي النافذ. هدف الدراسة: الإجابة عن سؤال مفاده: مدى بجاح تطويع القواعد القانونية المنظمة للكاتب بالعدل التقليدي، للانطباق على جهة التوثيق الالكتروني في التشريع العراقي النافذ، بما يكفل زيادة الائتمان

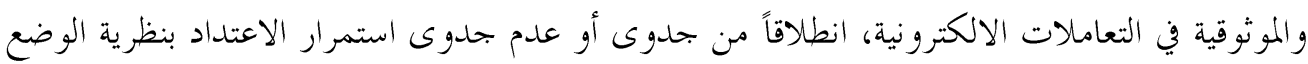
الظاهر، متت ما تو افرت شروطها، على التعاملات الالكترونية المعاصرة، وبالنتيجة، توجيه عناية وزارة

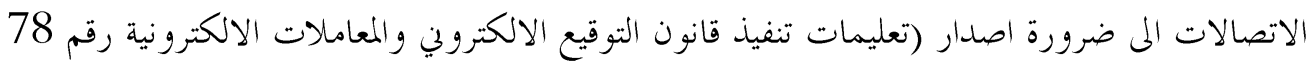
لسنة 2012)، عبر تقلديم اطار عام وشامل حول الموضوع، برؤية أكاديمية شبه متكاملة قد تعين الباحثين والمختصين على ذلك. منهجية الدراسة: اتبعت في هذ الدراسة منهجية التحليل النظري، عبر استطلاع وتحديد معالم النصوص

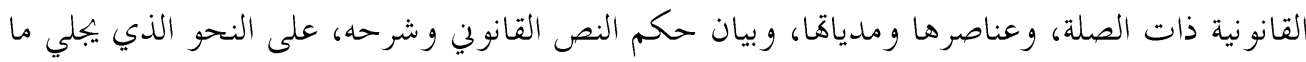

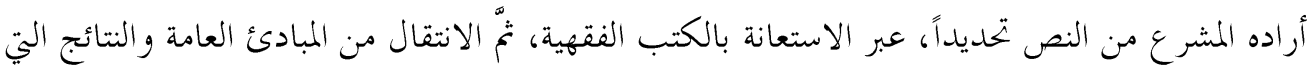


تقوم على البديهيات والمسلمات العلمية الى الجزئيات والاستنتاجات الفرعية، فعلى سبيل المثال، تتناول غالبية مراجع الدراسة التعاملات الالكترونية بشكل عام، فجرت محاولة تطويعها واسقاطها على لمئل موضوع الدراسة للخروج بهكم قانو ني له سند من صحيح القانون. تصميم الدراسة:

بغية الإحاطة بالموضوع، قدر الإمكان، قسمت الدراسة على مبحثين، وفق التصميم الآتي:

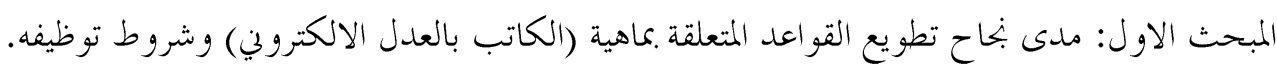
المطلب الاول: تطويع قو اعد الماهية وتحديد المفهوم. المطلب الثاني: تطويع قو اعد شروط التوظيف و التشكيل. المبحث الثاني: مدى بناح تطويع القو اعد المتعلقة بمهام (الكاتب بالعدل الالكتروني) والتزاماته.

$$
\text { المطلب الاول: تطويع قواعد المهام وآليات العمل. }
$$

\section{الاول: مدى نجاح تطويع القواعد المتعلقة بماهية (الكاتب بالعدل الالكتروبي) وشروط}

توظيفه

بسبب سكوت التشريع العراقي النافذ عن بيان ماهية (الكاتب بالعدل الالكتروني) وشروط توظيفه؛

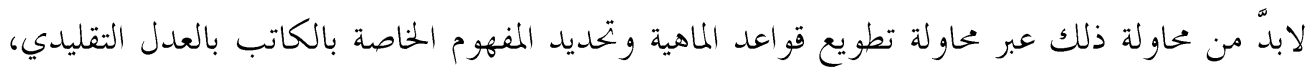

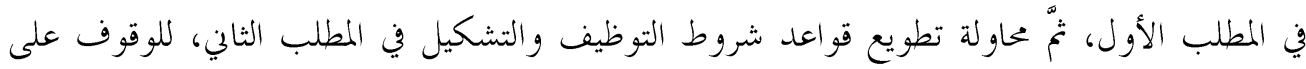
مدى بنحاح ذلك من عدمه، وعلى النحو الآتي:

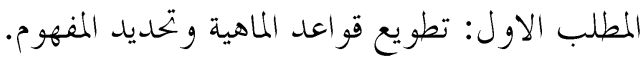
المطلب الثاني: تطويع قو اعد شروط التوظيف و التشكيل.

\section{المطلب الاول: تطويع قو اعد الماهية وتحديد المفهوم}

لم يورد قانون كتاب العدول رقم (23) لسنة 1998 (النافذ)، تعريفاً محدداً للكاتب بالعدل، إلا ان

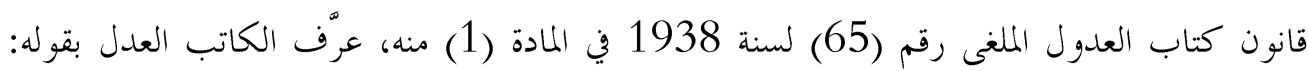

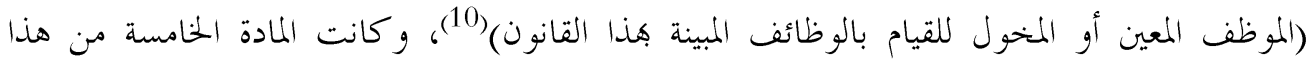
القانون قد بينت وظائف الكاتب العدل والمهام الملقاة على عاتقه، وهي تتلخص بتنظيم وتوثيق العقود

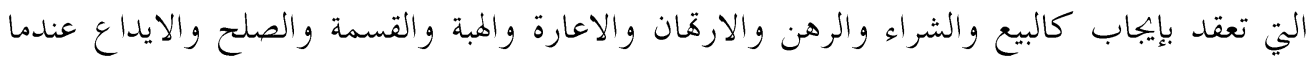


تكون متعلقة بمال منقول، وعقود الايمار والاسئيجار والاتفاقات والالتزامات المتعلقة بالأموال المنقول

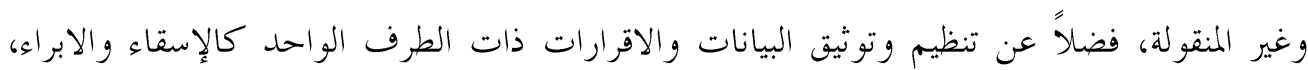

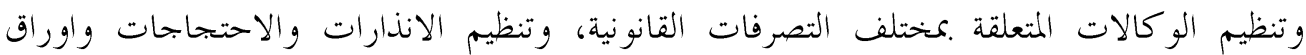
الاستفسار الخاصة بالسندات التجارية و كذلك تنظيم وتوثيق الانذارات الاخرى وتبليغها الم يخاطبها،

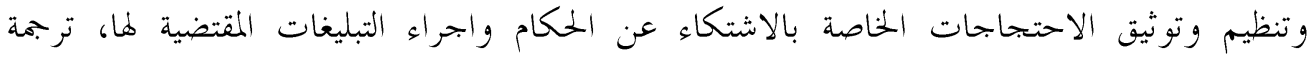

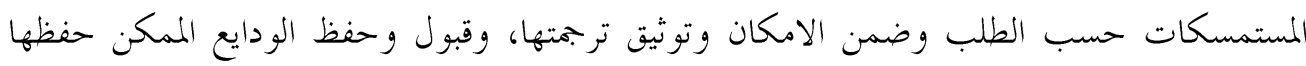

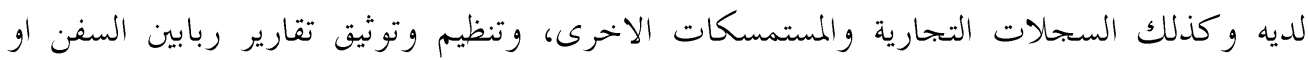

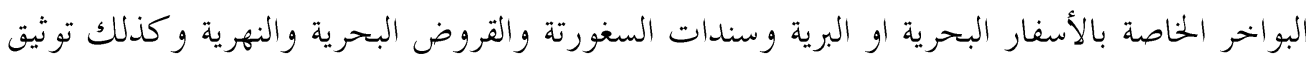

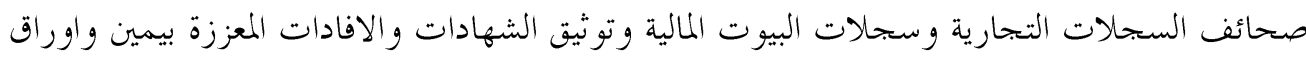

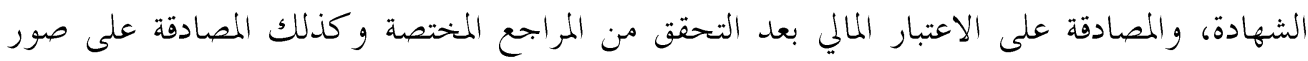

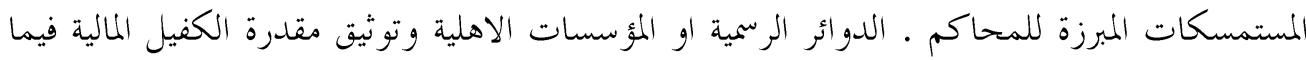

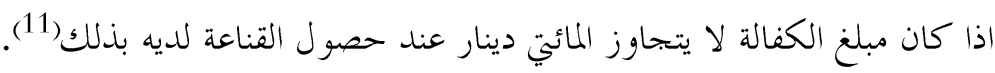

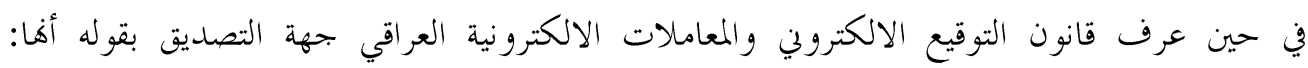

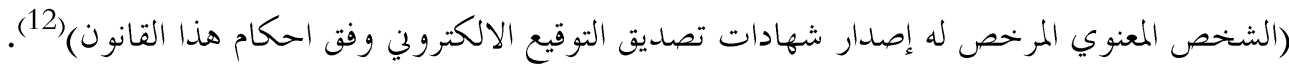

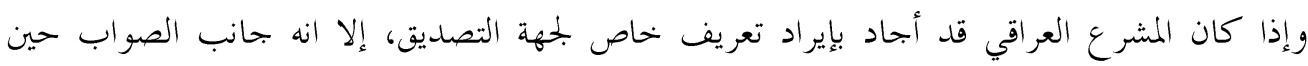

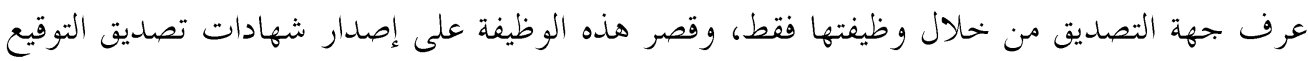

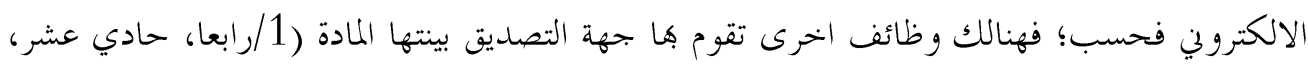

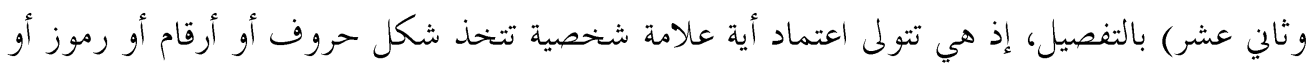

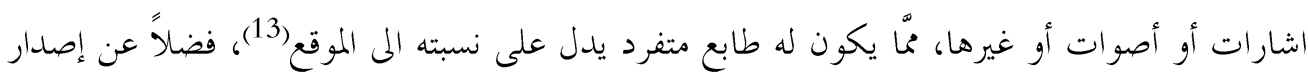

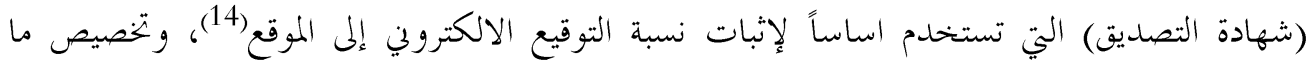

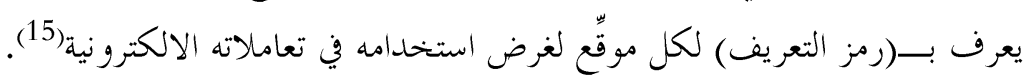

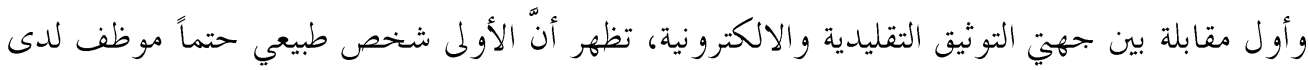

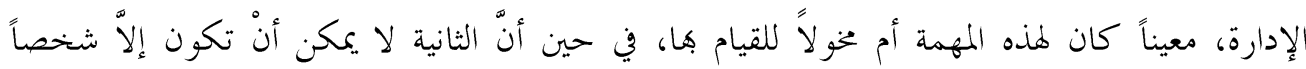

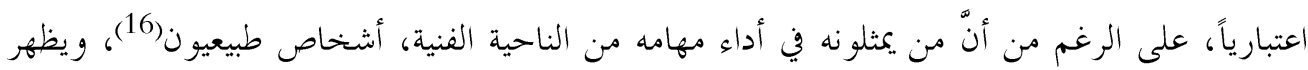

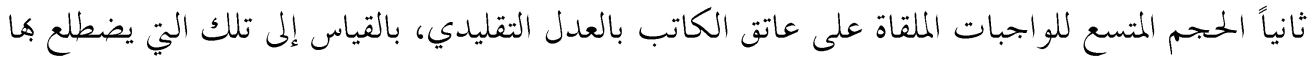

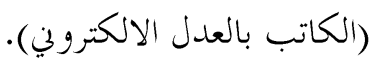




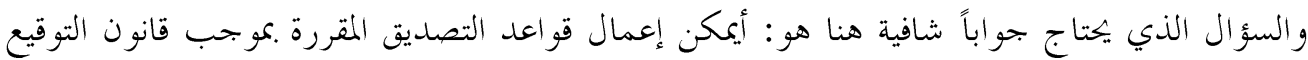

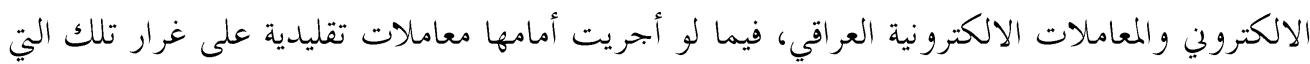

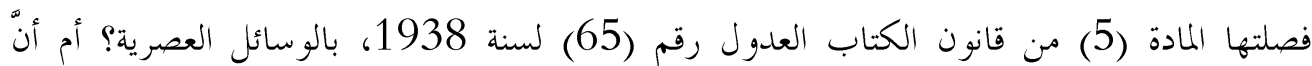
اختصاص جهة التصديق مقصور على ما أوردته الفقرات (رابعاً، حادي عشر، وثاني عشر من المادة 1)

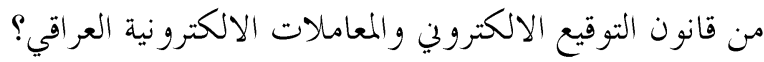

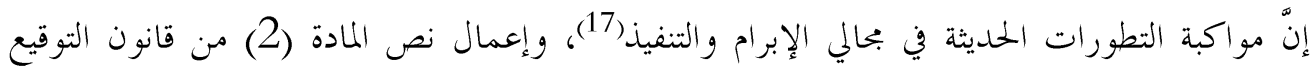

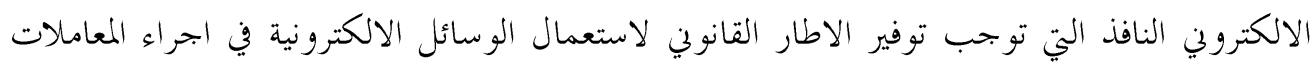

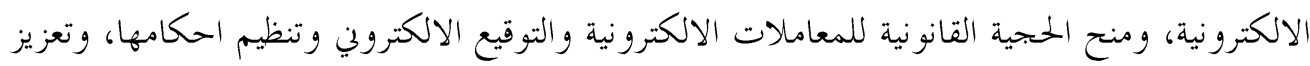

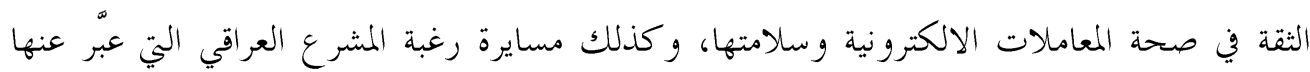

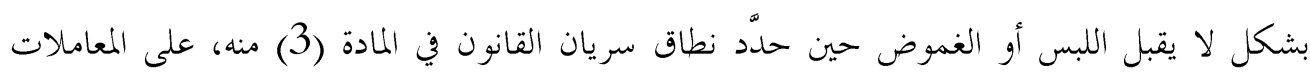

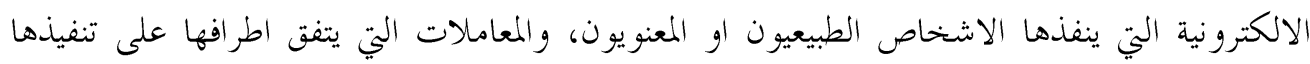

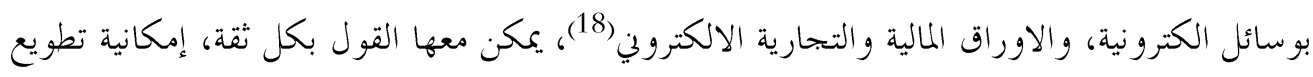
هذه النصوص التي تحكم -بالأصل-عمل الكاتب بالعدل التقليدي، للتطبيق على جهة التوثيق والتصديق التهريق الالكتروبي.

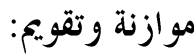

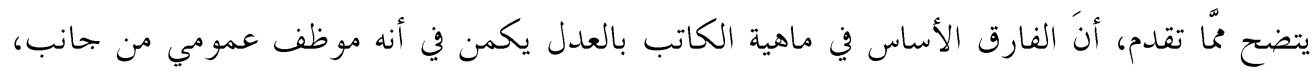

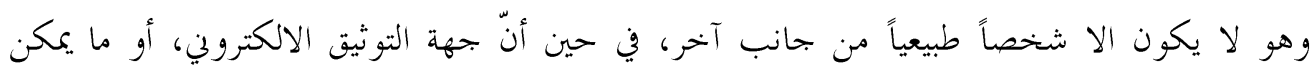

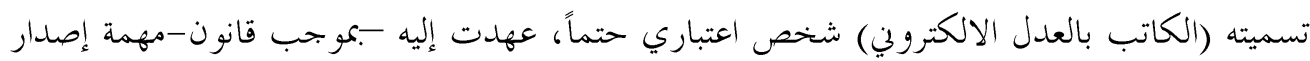

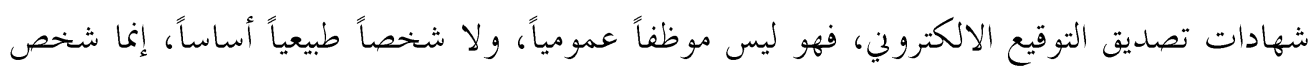

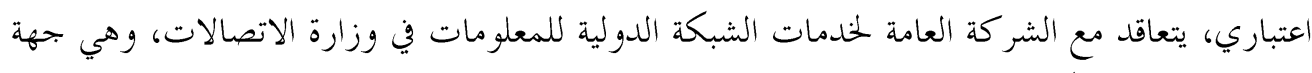

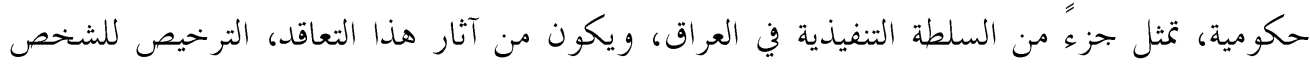

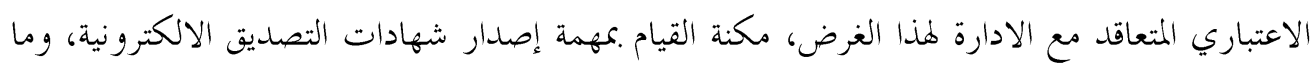

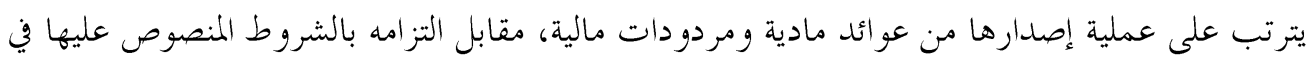
قانون التوقيع الالكتروني والمعاملات الالكترونية العراقي (19).

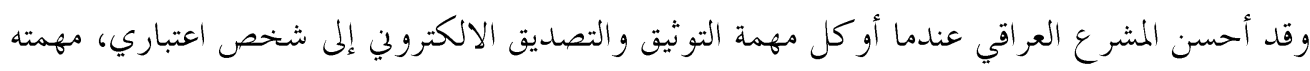

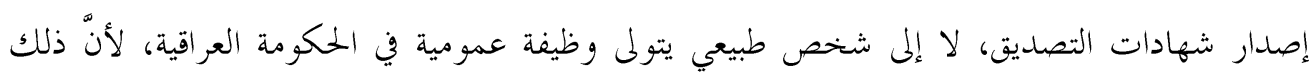


يتيح فاعلية في بحال الرقابة وتقويم الأداء، بشكل يضمن جودة أدائها مهامها من النواحي الفنية(20)،

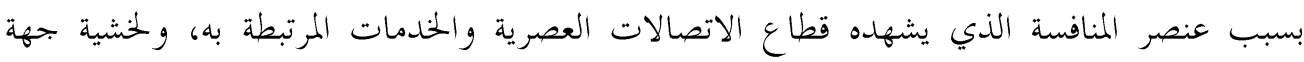
التوثيق من استعمال وزارة الاتصالات صلاحيتها القانونية في سحب الترخيص، لدى إخلالها بالتزاماها

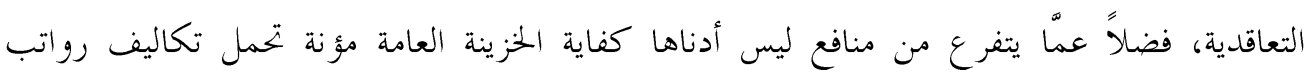

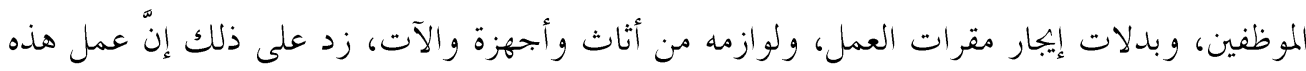

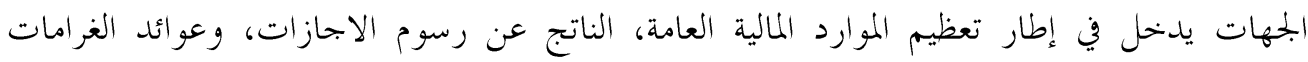

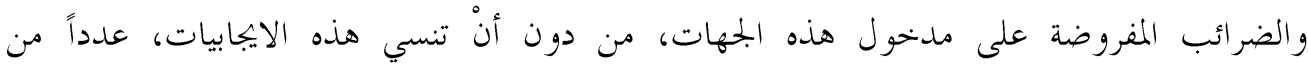

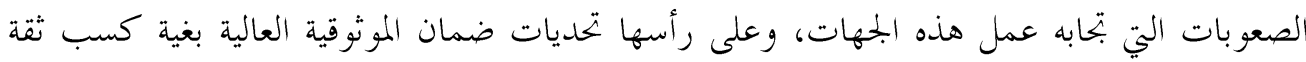

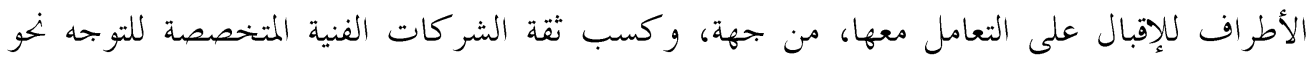

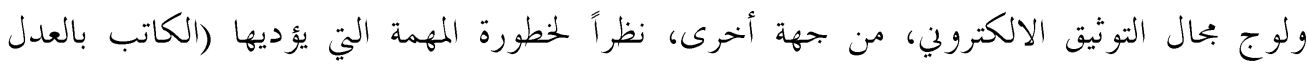

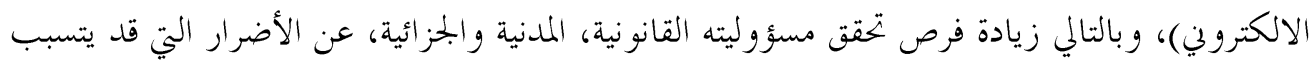

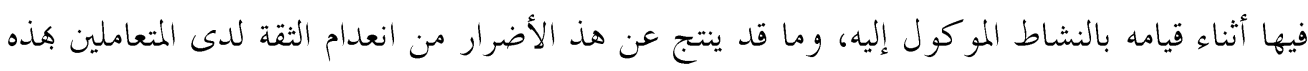

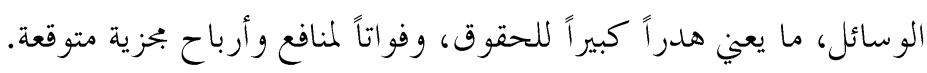

\section{المطلب الثالي: تطويع قواعد شروط التوظيف والتشكيل}

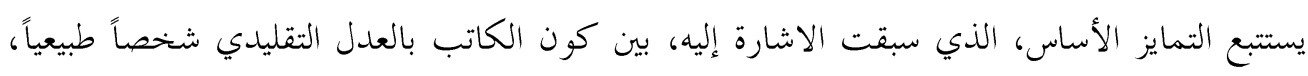

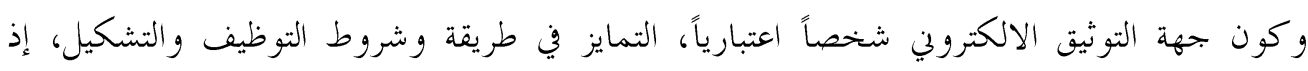

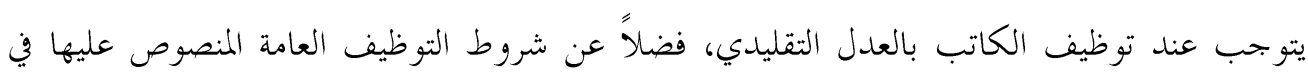

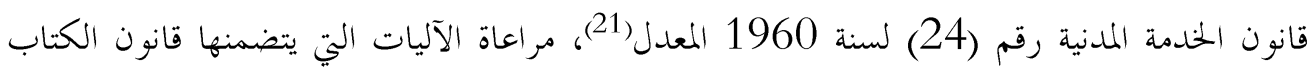

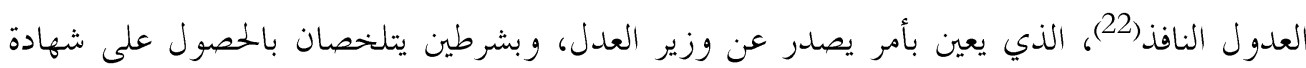

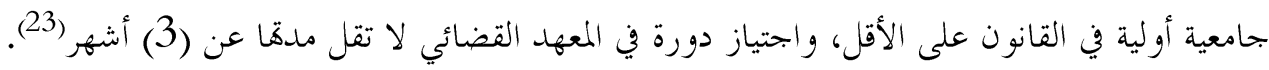

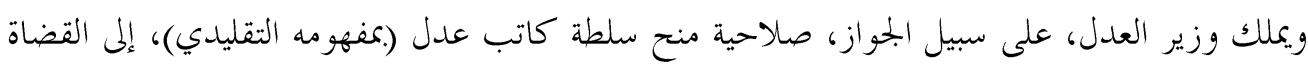

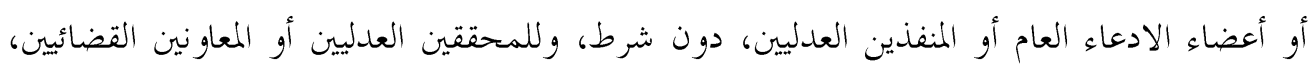

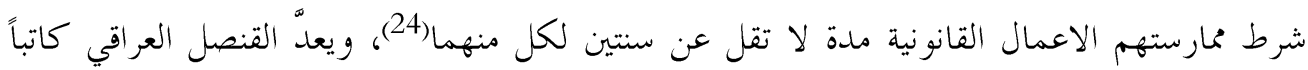

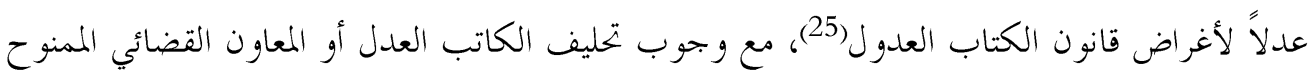

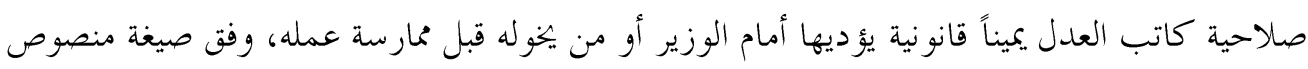
عليها قانوناً).26). 
وإزاء سكوت قانون التوقيع الالكتروني، عن بيان الشروط المتعلقة بـــــالكاتب بالعدل الالكتروفي)

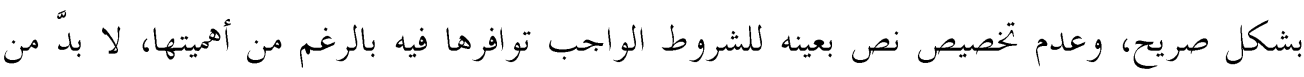
استقراء مو اد القانون بقصد استجلاء هذه الشروط بشكل ضمني بين طياته، ولعلّ من أهمها: 1. أن تتوافر للمرخص له موارسة مهنة تصديق التواقيع الالكترونية المستلزمات البشرية والمادية (27) 2. تقديم المرخص له، كفالة ضامنة للوفاء بالغرامات أو التعويضات أو الالتزامات المالية الاخرى، وأن تبقى الكفالة قائمة طيلة مدة الترخيص(28).

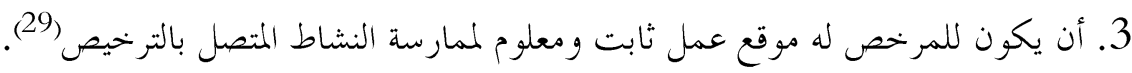

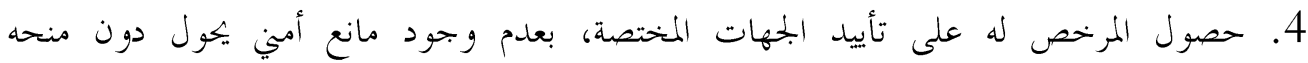
الترخيص (30) ويلاحظ ورود هذه الشروط ضمن التزامات الشركة العامة لخدمات الشبكة الدولية للمعلومات في وزارة الاتصالات، ووجوب مراعاتا عند منح الترخيص .مزاولة نشاط اصدار شهادة التصديق، وكان الاجددر بالمشرع إيراد شروط ممارسة التوثيق بجتمعة في مادة واحدة، على غرار ما فعل، حين حدد مدرد شروط حيازة التوقيع الالكتروني حجية الاثبات القانونية(31). 5. عدم جواز مزاولة نشاط اصدار شهادة التصديق دون الحصول على على ترخيص وفت وفت أحكام قانون التوقيع الالكتروني(32)، وهو نص معيب؛ بالنظر لأسلوبه المخالف لأصول الصياغة التشريعية؛ إذ ترجح اعتبارات اللغة عند صياغة الكلام، التعبير الايجابي على التعبير السبي، باستخدام صيغة الاثبات بدل لهرل

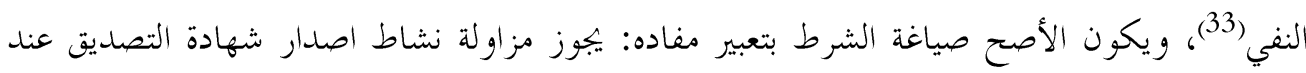
الحصول على الترخيص وفق أحكام هذا القانون، فدلَ مفهوم المخحالفة على المنع، كما أنَّ من الجائز

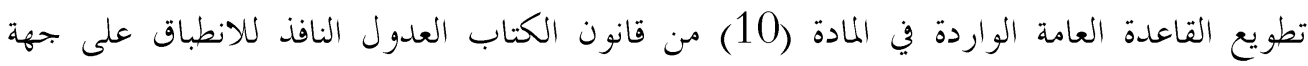
التصديق و التوثيق الالكترونية، عبر إجازة عدّ القنصل العراقي جهة توثيق الكتروفي لأغراض هذا هار القانون وفق أحكام المادة (10) من قانون الكتاب العدول شريطة توفير متطلبات الدعم الفين اللازمة لأداء مهماته. أما بشأن إمكان أو عدم إمكان تطويع مضمون نص المادة (7) من قانون الكتاب العدول، الخاص بمنح صلاحية الكاتب العدل إلى القضاة أو أعضاء الادعاء العام أو المنفذين العدليين، مطلقاً، والمحققين العدليين أو المعاونين القضائي لدى ممارستهم الاعمال القانونية مدة لا تقل عن سنتين لكل منهما، 
فالر اجح عم إمكان ذلك؛ لأنَّ في منحهم مثل هذه الصلاحية خروجاً على المهام الرئيسة التي يضطلع ها

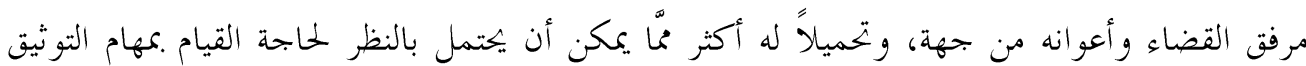
الالكترو ني إمكانات دعم فين ولوجستي ربما لا يتو افر عليها القضاة أو أعو اهم.

المبحث الثالي: مدى نجاح تطويع القواعد المتعلقة بمهام (الكاتب بالعدل الالكترولي) والتز اماته يلعب الكاتب بالعدل دورا فاعلاً في استقرار المعاملات التي تجرى من قبله أو من قبل الأطراف المعنية

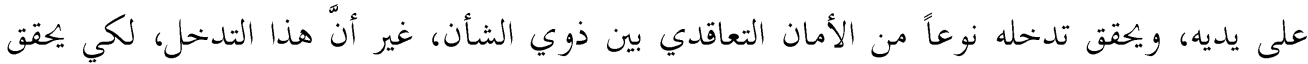

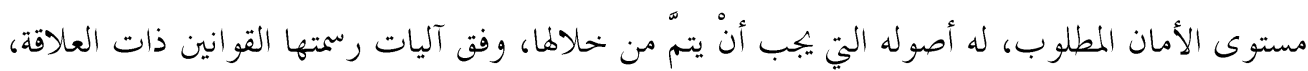
في حدود سلطات دوائر الكتاب العدول واختصاصاها المرسومة(34)، وبغية تحديد الآليات وبيان الالتزامات، قسّم هذا المبحث على مطلبين، كما يأتي: المطلب الاول: تطويع قواعد مهام وآليات عمل جهات التوثيق. المطلب الثاني: تطويع حدود التزامات جهات التوثيق وواجباتها.

\section{المطلب الاول: تطويع قو اعد مهام وآليات عمل جهات الثوثيق}

تختلف مهام وآليات عمل الكاتب بالعدل التقليدي، عن تلك الخاصة بجهات التوثيق الالكترونية، ما يوجب تقسيم هذا المطلب على فرعين، كما يأتي: الفرع الاول: مهام الكاتب بالعدل التقليدي. الفرع الثاني: مهام جهة التوثيق الالكتروي.

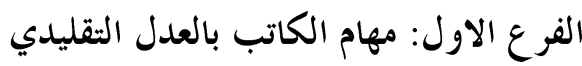

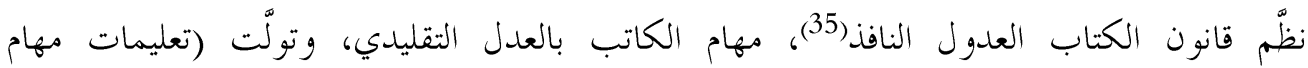

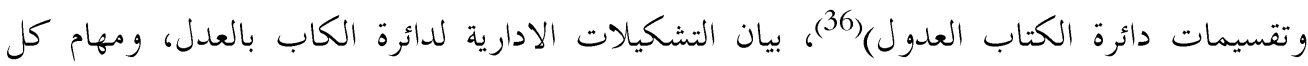
منها(37) وتتجلَّى المهمة الأولى التي يضطلع بها الكاتب بالعدل التقليدي، في تنظيم وتوثيق التصرفات القانونية التي تشترط القوانين، أو يرغب أطراف العلاقة توثيقها، مع ملاحظة استثناء التصرفات التي اشترطت القانون

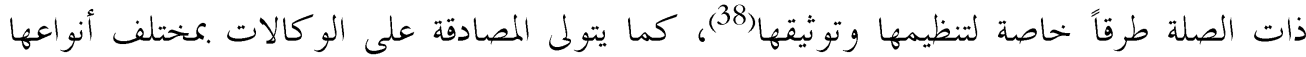

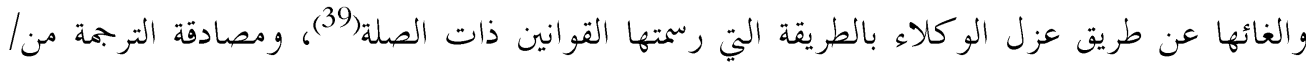

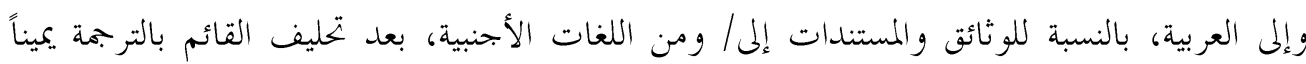


قانونية على صحة الترجمة ومطابقتها للأصل، لغرض اعتمادها بشكل رمسمي من قبل الجهات العراقية

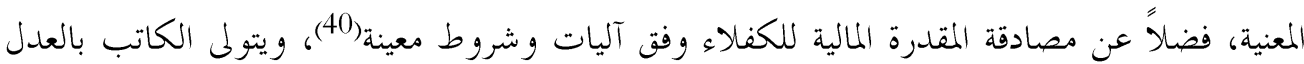

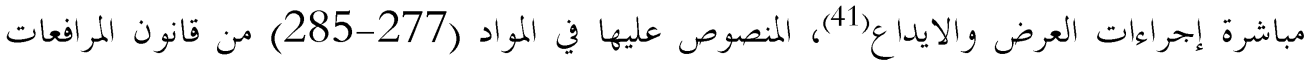
المدنية النافذ(42)، إذ يقبل الكاتب بالعدل الودائع النقدية والعينية والسندات وفق الآليات والشروط التئي عينتها المو اد المذكورة(43).

ومن المعلوم أنَ التشريع العراقي خصِّ دائرة الكاتب العدل بسلطة تسجيل المكائن في الحدود الادارية للمنطقة الموجودة فيها الماكنة، وقرر عدم الاعتداد بالتصرفات القانونية على المكائن المشمولة بالتسجيل،

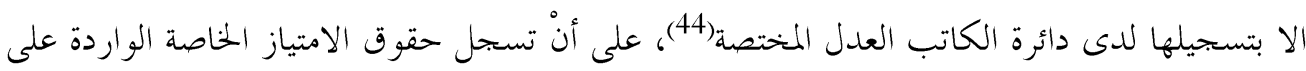

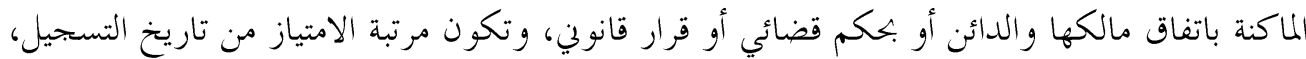
مع مراعاة النصوص القانونية ذات العلاقة(45). الفرع الثاين: مهام جهة التوثيق الالكتروبي على خلاف تصريح قانون الكتاب العدول رقم (33) لسنة 1998، بالمهام الملقاة على عاتق الكاتب

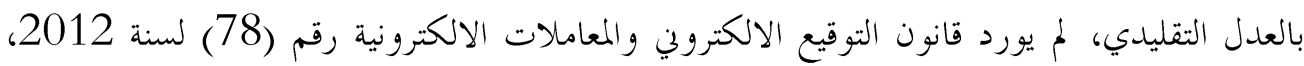

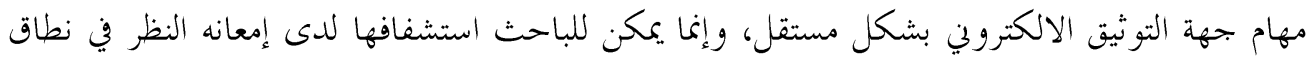

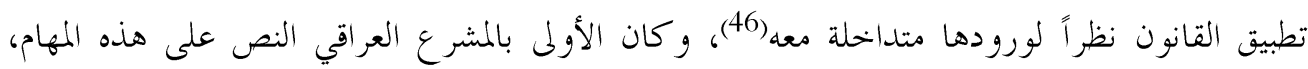

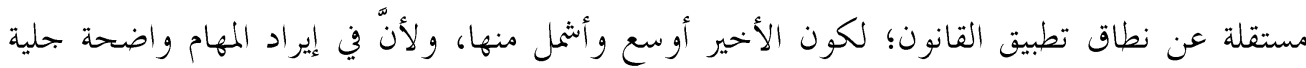

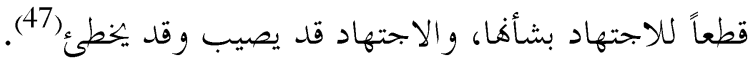
إذ تسري أحكام قانون التوقيع الالكتروني العراقي النافذ، على المعاملات الالكترونية التي ينفذهائ

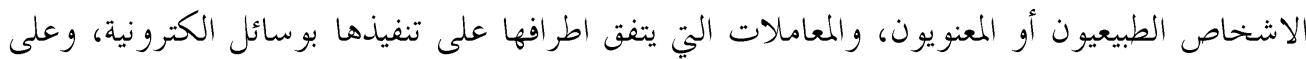

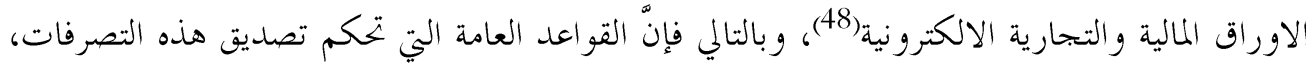

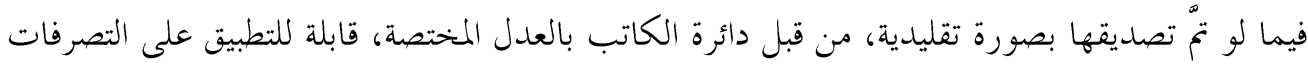

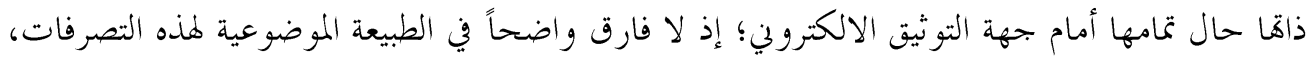

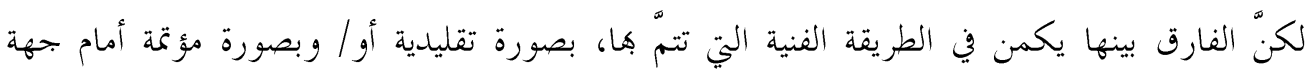

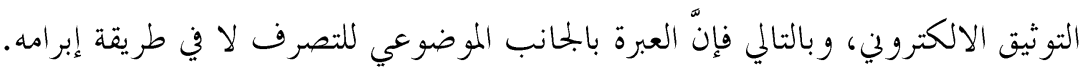

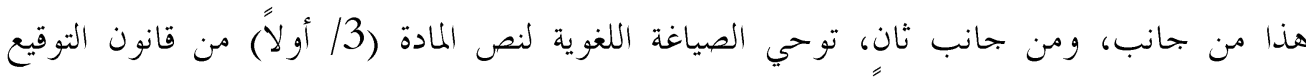

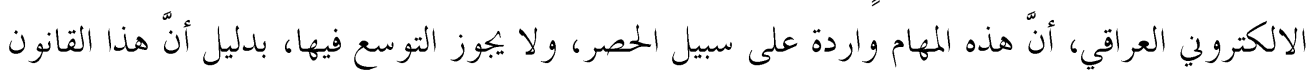


ذاته، نصّّ على استثناء عدد من المعاملات من نطاق تطبيقه، وهي تحديداً المعاملات المتعلقة بمسائل

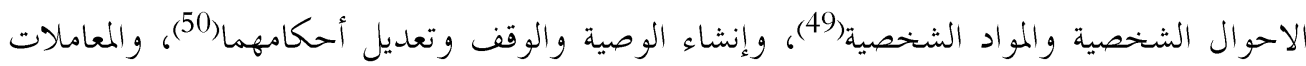

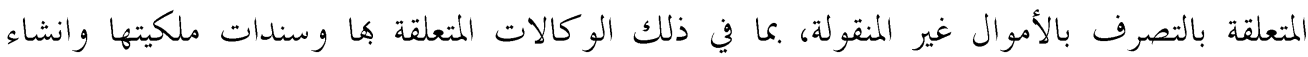

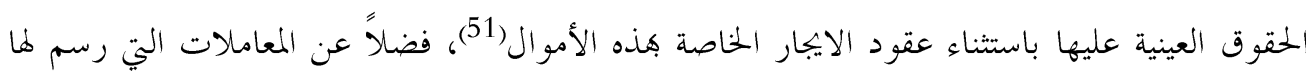

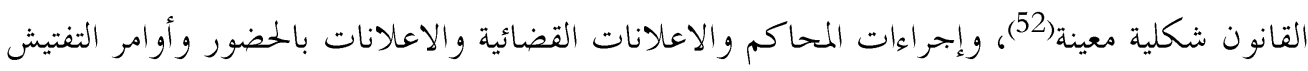

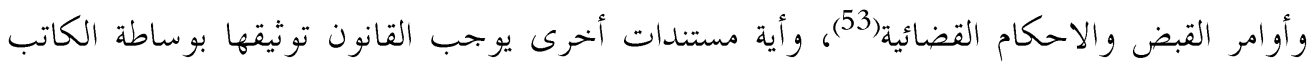
بالعدل التقليدي(54) إنَّ النتيجة المنطقية لهذا النصة، هي عدم سريان الأحكام الواردة في قانون التوقيع الالكتروفي على هذه

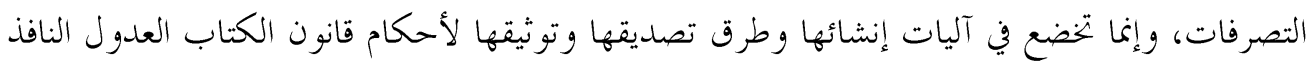

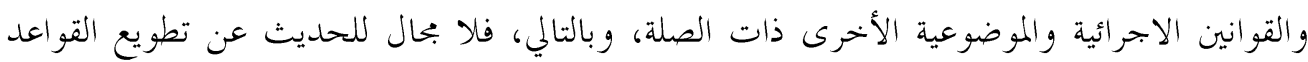

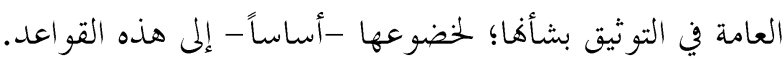

\section{المطلب الثاين: تطويع قواعد الالتزامات و الواجبات}

لا شكَّ أنّ مهام وآليات عمل الكاتب بالعدل التقليدي، تختلف عن تلك الخاصة بجهات التهات التوثيق الالكترونية، ما يوجب تقسيم المطلب على فرعين، لغرض بيان تلك المهام والالتزامات، وعلى النحو الآتي: الفرع الاول: التزامات الكاتب بالعدل التقليدي. الفرع الثاني: التزامات جهة التوثيق الالكتروني. الفرع الاول: التزامات الكاتب بالعدل التقليدي تتصل الالتزامات الملقاة على عاتق الكاتب بالعدل بطبيعة القواعد والأصول التي تقوم عليها مهنته، والتي

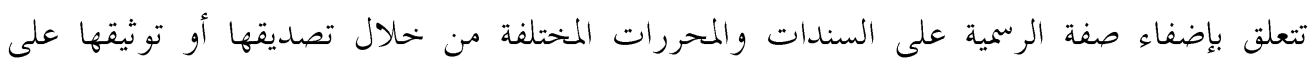

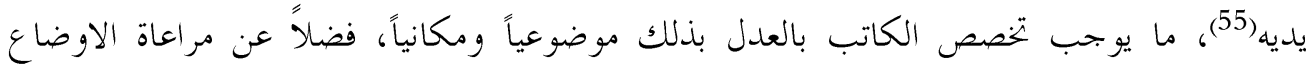
و الشكليات التي فرضتها القوانين المختصة، واستيفاء الرسوم المفروضة لإكمال هذه الإجراءات لحسبات لحساب

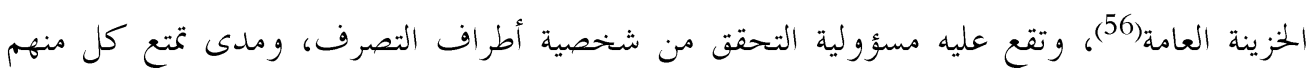
بالأهلية القانونية، عبر تكليفهم تقديم الأوراق الرسمية المثبتة لشخصياقمى (57).

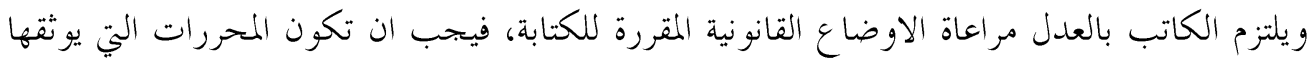

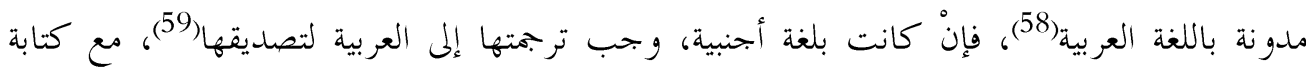




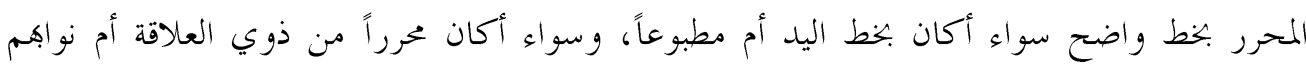

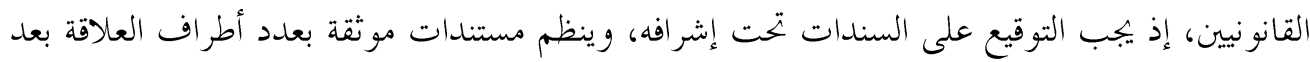

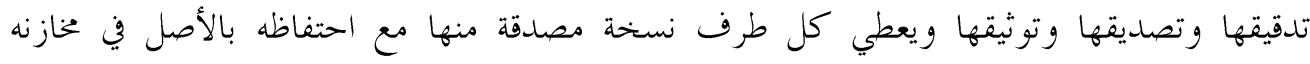

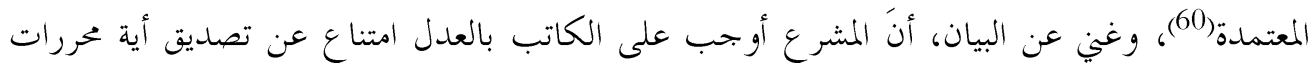

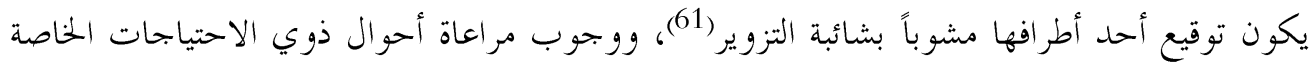

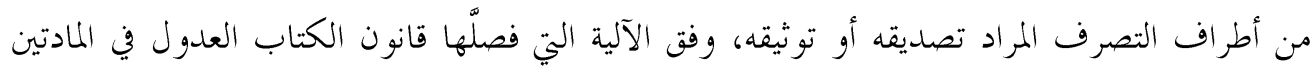

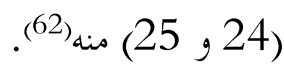

ولا تقتصر التزامات الكاتب بالعدل على مرجلة انشاء السند المتعلق بالتصرف محل التصديق او التوثيق،

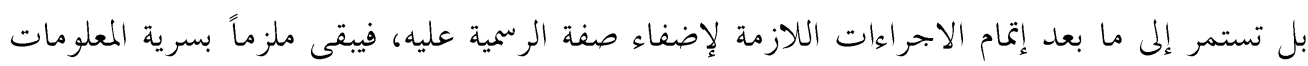

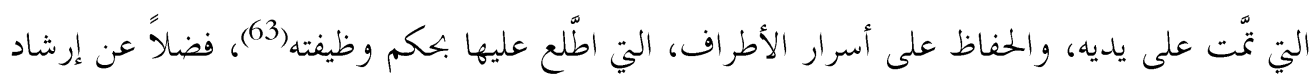

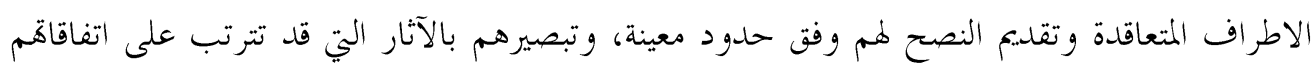
المختلفة (64).

\section{الفرع الثالي: التزامات جهة التوثيق الالكتروبين}

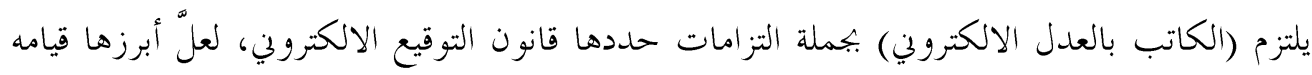

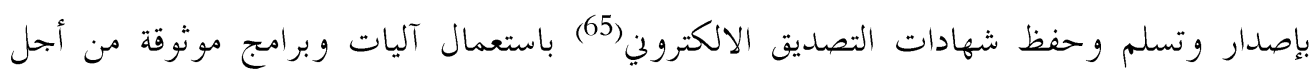

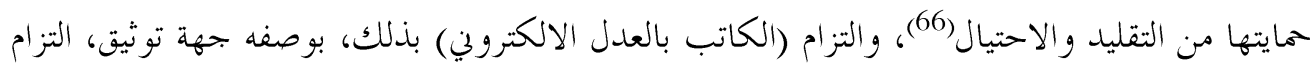

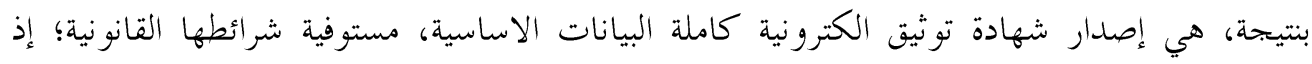

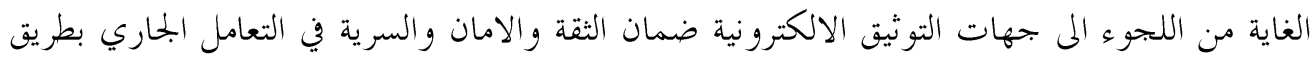
الكتروين (67).

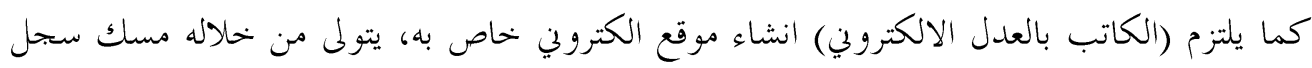

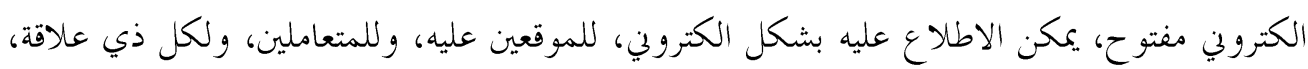

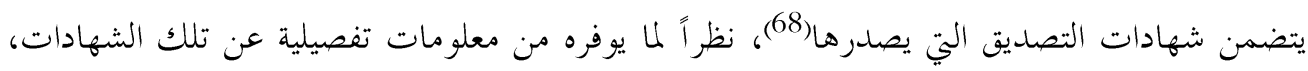

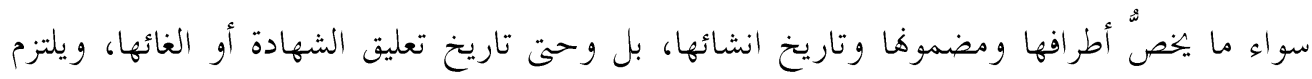
حمايته من التغيير غير المشروع (69) 
كما يلتزم ضمان صحة المعلومات المصادق عليها في الشهادة اعتبار اً من تاريخ تسلمها من ذوي العلاقة، وضمان صدقية الصلة بين الموقع ومنظومة التدقيق و المراجعة الخاصة بتوقيعه و انفر اد الموقع بمسك منظومة انشاء توقيعه الالكتروون(70).

وأوجب المشرع العراقي على (الكاتب بالعدل الالكتروني) إصدار أمر بتعليق العمل بشهادة التصديق

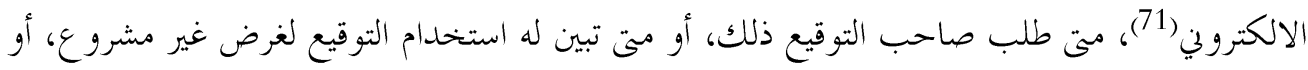
أن المعلومات التي يجتو يها المحرر الموقع تغيرت(72).

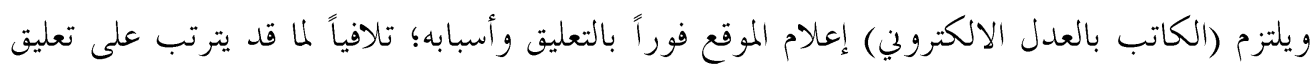

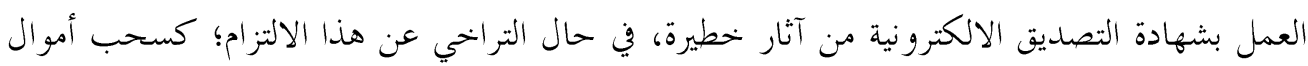

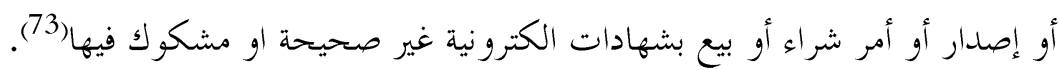

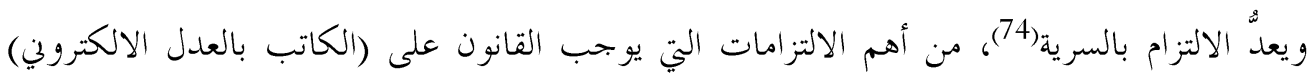

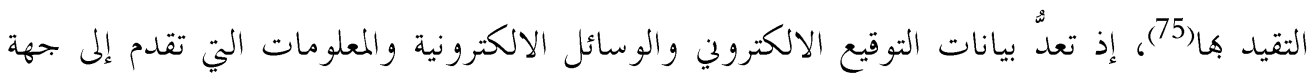

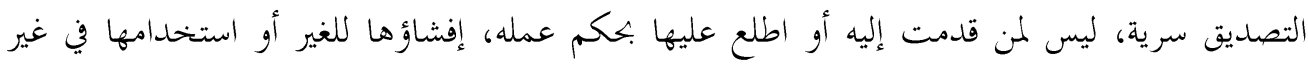
الغرض الذي قدمت من أجله (76).

ويلتزم (الكاتب بالعدل الالكتروني)، شأنه في ذلك شأن أية جهة أو مؤسسة حكومية أو خاصة، تزويد الشركة العامة للاتصالات، أو المحكمة المختصة عندما تقرر ذلك، .ما تطلبه من تقارير ومعلومات

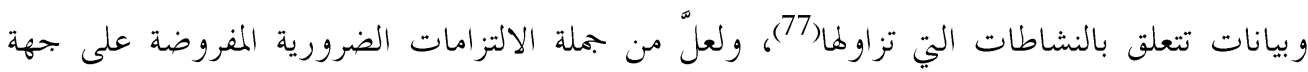
التوثيق، وجوب استمرار تعديل وتحديث بياناها بصورة دورية منتظمة، بما يضمن مطابقة البيانات للو اقع (78).

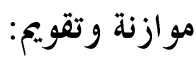

من خلال مقارنة ماهية ومهام والتزامات الكاتب بالعدل وجهة التوثيق الالكتروفي، يمكن القول بإمكانية إعمال وتطويع جزء من القواعد العامة والنصوص المنظمة لعمل الكاتب بالعدل، للانطباق على جهات

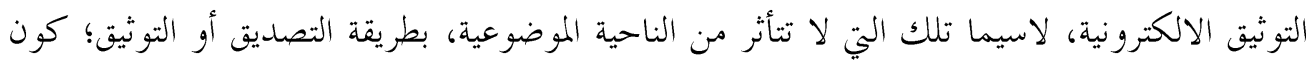

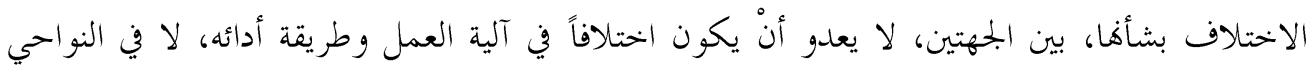

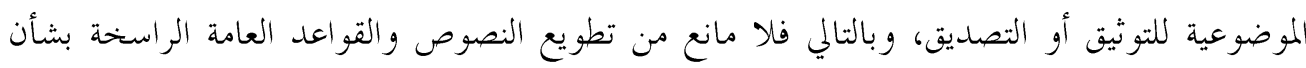

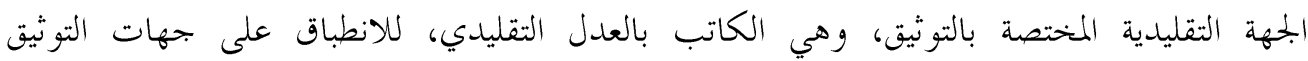


الالكترونية، فيما لم يرد بشأنه حكم أو نص في قانون التوقيع الالكتروفي والمعاملات الالكترونية العراقي رقم (78) السنة 2012.

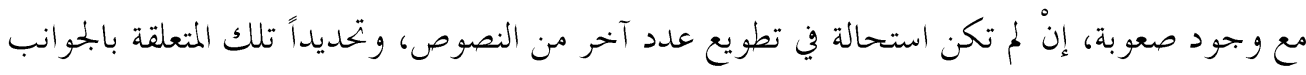

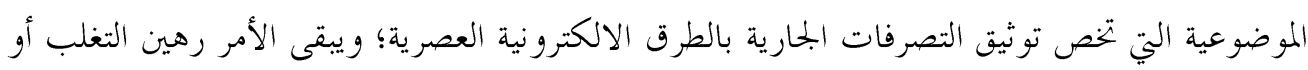

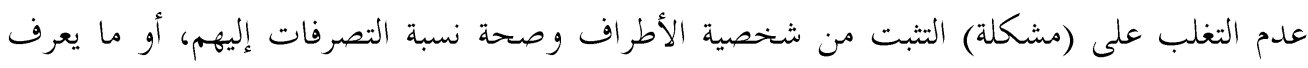

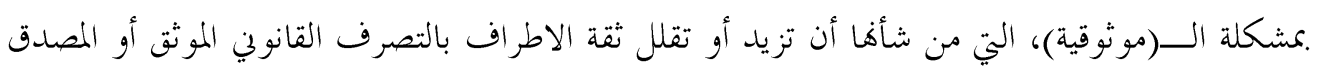

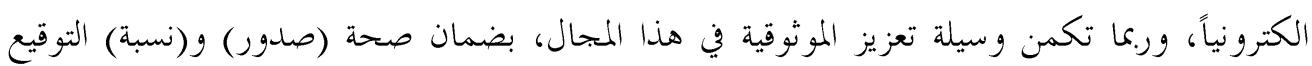

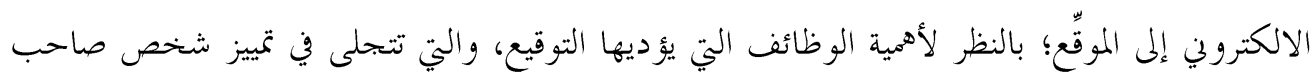
التوقيع من غيره، وتحديد شخصيته وهويته، و بالتالي أهليته أو عدم أهليته القانونية، وتعبيره عن مو افقتنه

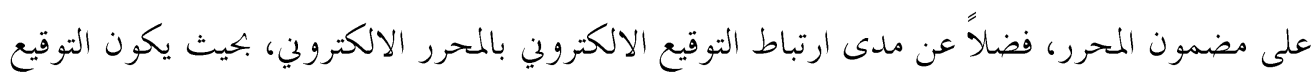
دليلاً قاطعاً على شخص صاحبه، وضامناً لسلامة بيانات المحرر الالكترو ني (79).

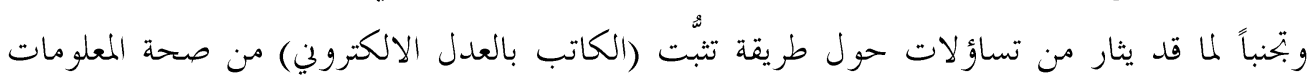

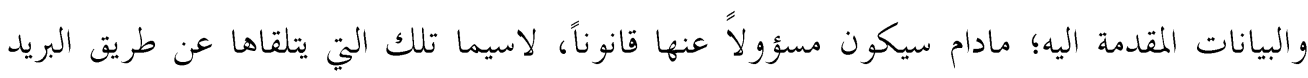

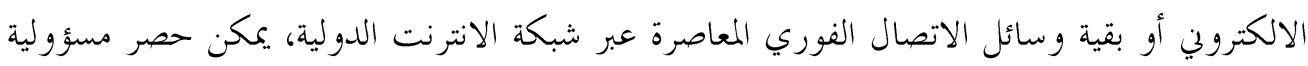

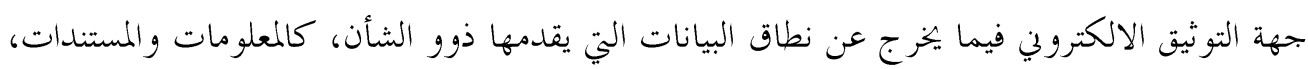

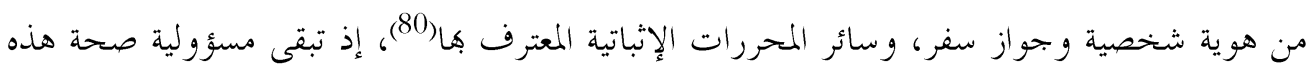

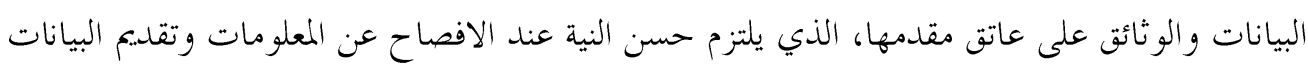

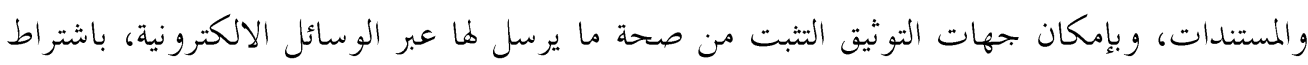

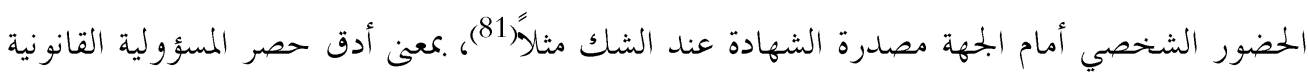

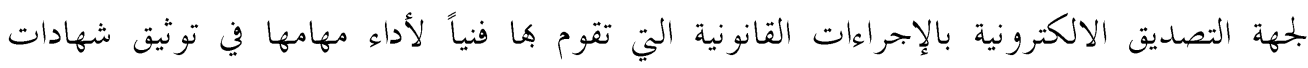

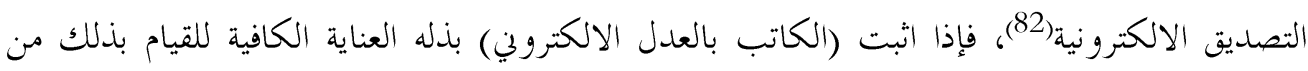

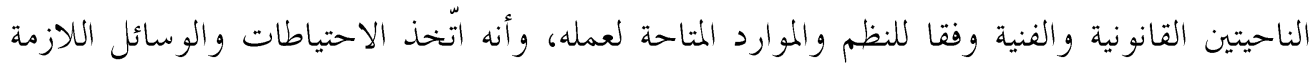

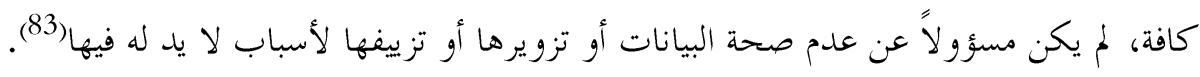

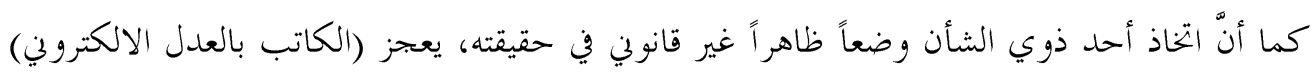

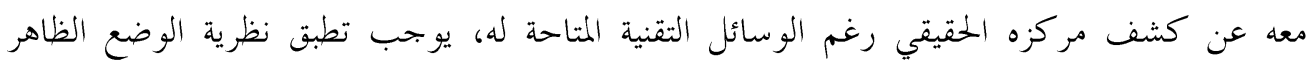

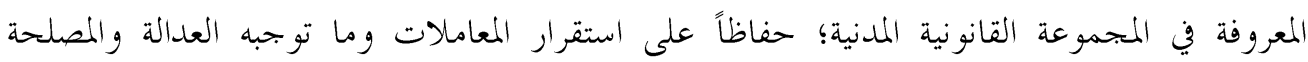


العامة(84)، لاسيما بالنسبة للغير حسن نية، المتعامل مع صاحب الوضع الظاهر(85)، الذي اتخذ مظاهر

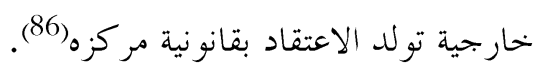

الحخاتمة:

يمكن -في ختام البحث- إيجاز أبرز النتائج والتوصيات التي تحَ التوصل إليها بالآتي:

$$
\text { أولاً: نتائج البحث: }
$$

1- م لم يورد قانون كتاب العدول رقم (23) لسنة 1998النافذ تعريفا خاصا للكاتب بالعدل، إلا ان ان قانون كتاب العدول الملغى رقم (65) لسنة 1938 في المادة (1) منه، عرف الكاتب العدل بقوله: (الموظف المعين او المخول للقيام بالوظائف المبينة هذا القانون) 2- - حسنا فعل قانون التوقيع الالكتروفي والمعاملات الالكترونية العر اقي عندما عرف جهة التصدين التصديق بقوله أها: (الشخص المعنوي المرخص له اصدار شهادات تصديق التوقيع الالكتروني وفق احكام

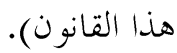
3- ان مشرع قانون التوقع الالكتروني والمعاملات الالكترونية قد جانب الصواب حين عرّف جهة التصديق من خحلال وظيفتها فقط، وقصر هذه الوظيفة على اصدار شهادات تصديق التوقيع

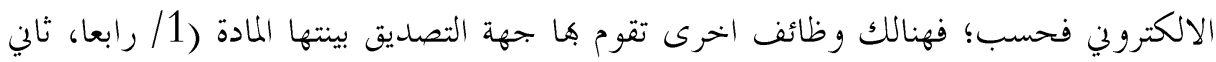
عشر ) بالتفصيل. 4- بين قانون كتاب العدول النافذ الشروط الخاصة بالكاتب بالعدل التقليدي في

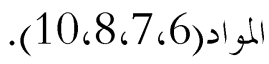
5- ملم يبين قانون التوقيع الالكتروفي والمعاملات الالكترونية الشروط المتعلقة بــ(الكاتب بالعدل

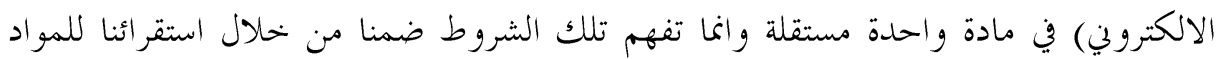
. 8، 7) 6- إنّ نص المادة (7) من قانون التوقيع الالكتروبي نص معيب؛ لأسلوبه المخحالف لأصول الصياغة

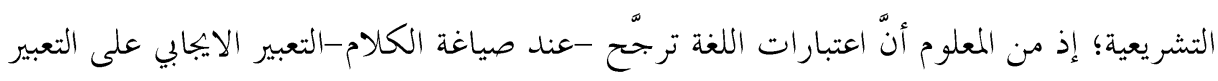

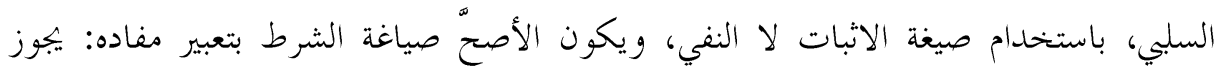
مزاولة نشاط إصدار شهادة التصديق عند الحصول على الترخيص وفق أحكام هذا القانون، ليدل مفهوم المخحالفة على المنع. 
7- يلعب الكاتب بالعدل دوراً كبيراً في استقرار المعاملات، وتحقيق الأمان التعاقدي بين الاطراف

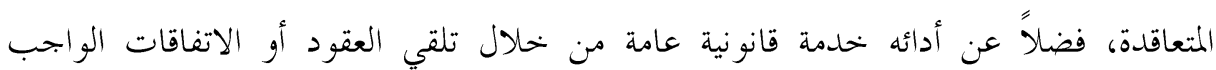
توثيقها، أو رغبة الاطراف المتعاقدة في اضفاء الطابع الرسمي عليها.

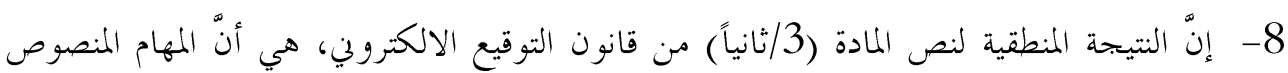

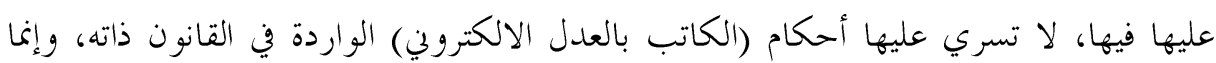
تخضع لأحكام قانون الكتاب العدول و القوانين الاجر ائية والموضوعية الأخرى ذات الصلة.

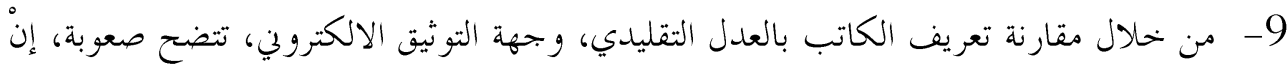
لم تكن استحالة، تطويع النصوص المتصلة بالتعريف والماهية؛ كون الكاتب بالعدل التقليدي

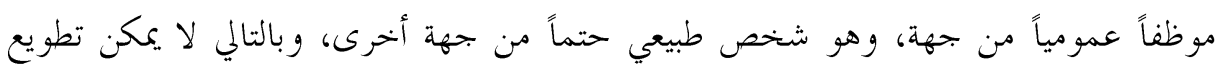

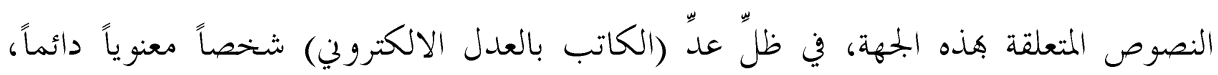
عهدت إليه مهمة إصدار شهادات تصديق التوقيع الالكتروني.

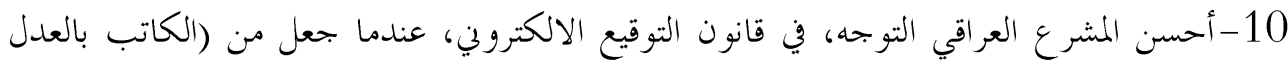

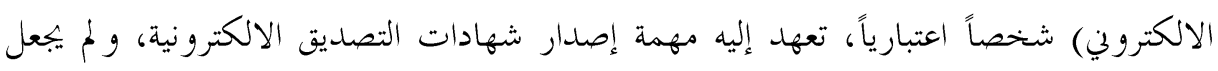

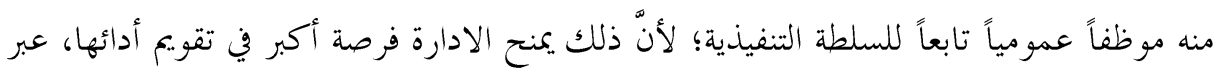
إخضاعها لرقابة الشركة العامة لخدمات الشبكة الدولية للمعلومات في وزارة الاتصالات العراقية. 11-إن التحدي الأكبر الذي يواجه (الكاتب بالعدل الالكتروبن) في أداء مهامه والتزاماته، يتمثل مكسألة (الموثوقية) من أشخاص وأهلية أطراف التصرف المراد تصديقه أو توثيقه، وهذه بمكن بكن.

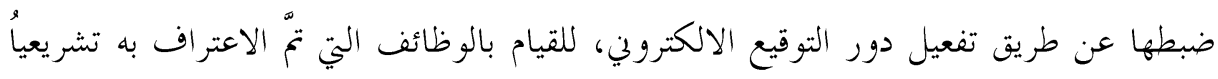
من أجل القيام ها، و كذلك تفعيل دور الرقابة على أداء مهامه والتزاماته على الوجه الأكمل.

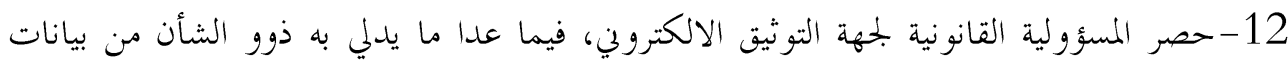

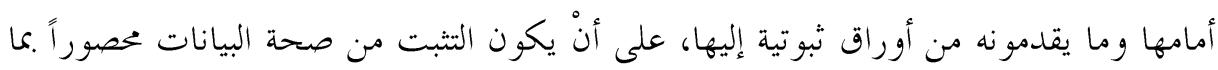

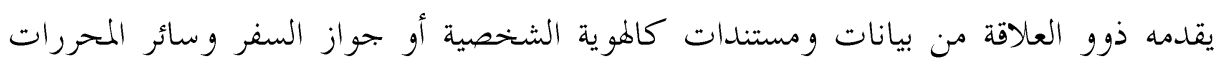

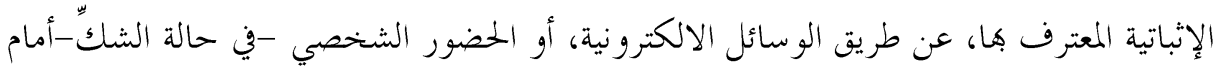
الجهة مصدرة الثهادة. 13-اذا أثبت (الكاتب بالعدل الالكتروني) بذله العناية الكافية، لم يكن مسؤولاً عن عدم صحة البيانات أو تزو يرها أو تزييفها لأسباب لا يد له له فيها. 
14-يجب تطبيق نظرية الوضع الظاهر المعروفة في المجموعة القانونية المدنية في حال التخذ أحد ذوي

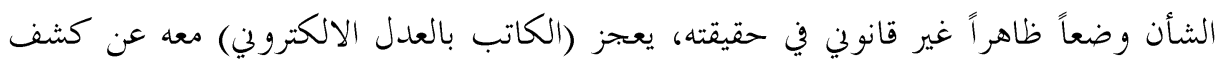
مر كزه الحقيقي رغم الو سائل الثقنية المتاحة له.

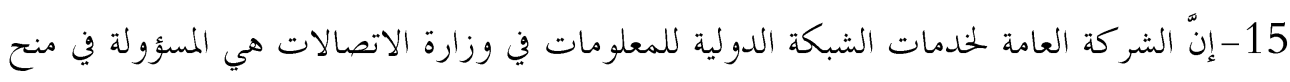
التراخيص المتعلقة بمزاولة نشاط اصدار شهادة التصديق. 16-جاءت نصوص قانون التوقيع الالكتروني والمعاملات الالكترونية خالية من النص على إمكانية الكانية

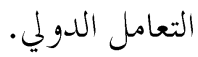
17- لم ينص قانون الثوقيع الالكتروفي على أية عقوبة في حال مخالفة (الكاتب بالعدل الالكتروني)

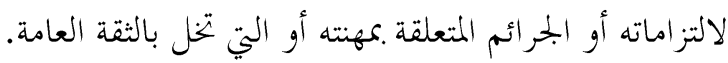

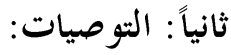
1- استحداث وظيفة تكون للمتخصص في علم الحاسبات وغيرها من العلوم التقنية ويكون الى

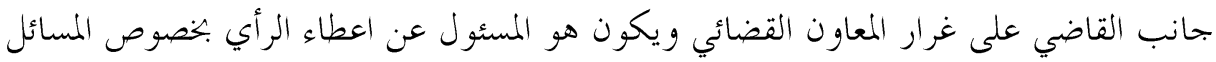
التقنية للقاضي؛ كون الخبرة غير كافية في هذا المجال.

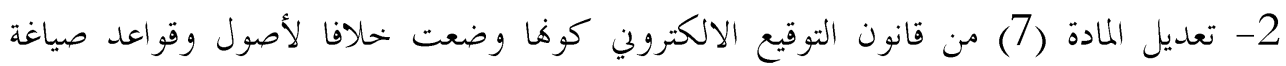

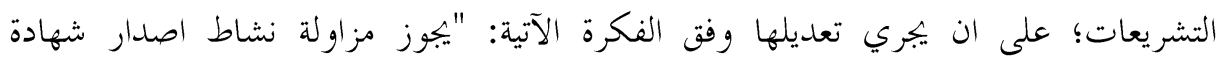
التصديق عند الحصول على الترخيص وفق احكام هذا القانون"، وبذلك فإن مفهوم المخالفة يدلنا على المنع. 3- إسراع وزارة الاتصالات بإصدار تعليمات تنفيذ قانون التوقيع الالكتروبي والمعاملات الالكترونية الصادر منذ عام 2012، وذلك للحاجة الماسة لها.

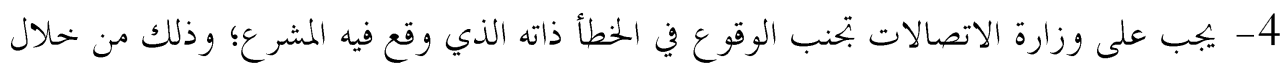

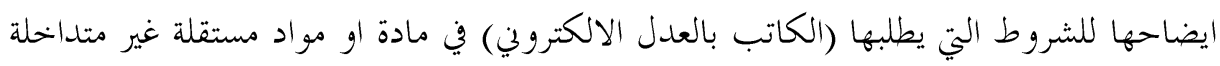

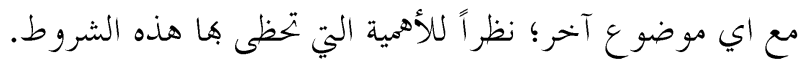

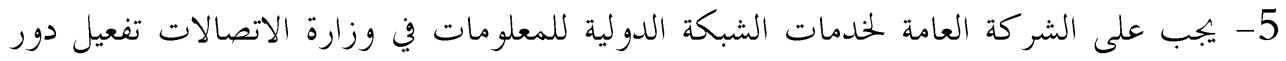

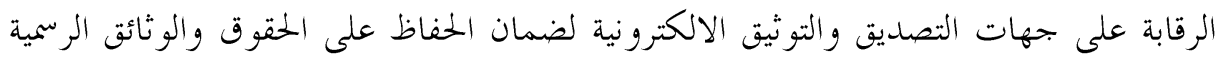
وغيرها. 
6- يجب على المشرع تجريم أفعال (الكاتب بالعدل الالكتروني) المخالفة لالتزاماته، وهي الأفعال الجرمية النابتحة عن ممارسته مهامه الوظيفية، وتلك المخلة بالثقة العامة، لاسيما في ظل خلو التشريع العقابي العراقي النافذ من مثل هذه النصوص، وعدم اصدار قانون جرائم المعلوماتية

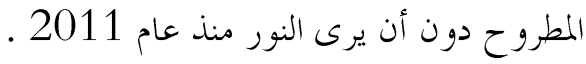
7- يجب على المشرع النص صراحة على امكانية إجراء التعاملات ذات الصبغة الدولية من خلال

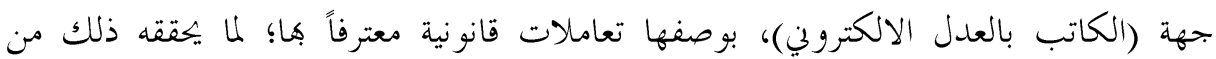
إيجابيات اقتصادية.

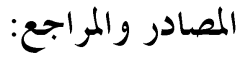

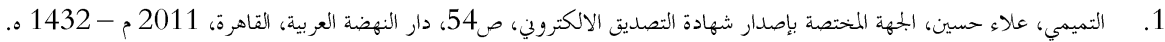

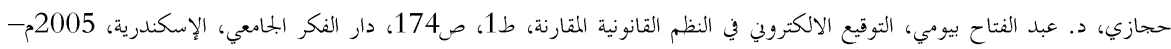

.01426

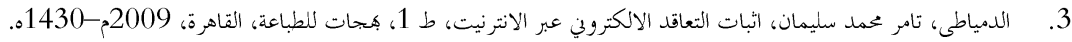

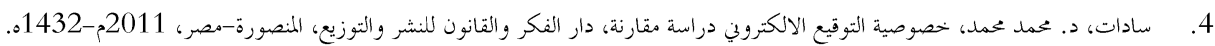

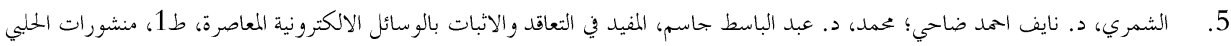

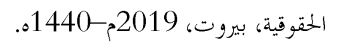

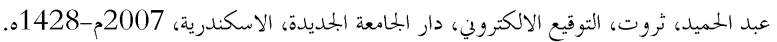

7.

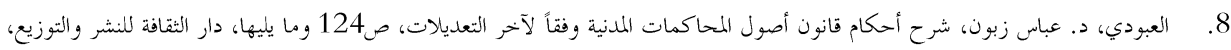

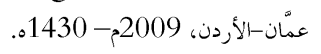

ا الفتلاوي، حسون علي حسون؛ الحسناوي، حسن حنتوش رشيد، التوقيع الالكتروفي في عقود التحارة الالكترونية، كلية القانون جامعة بابل،

2006 2006 م- 1427.

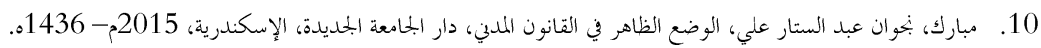

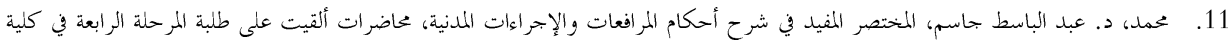

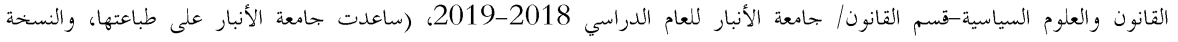

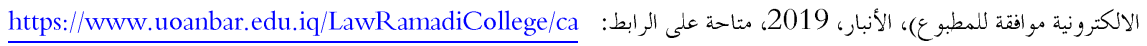

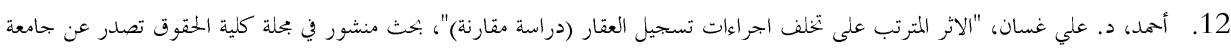

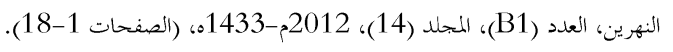

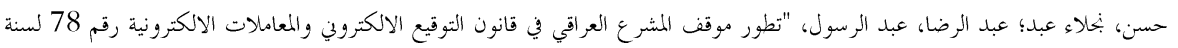

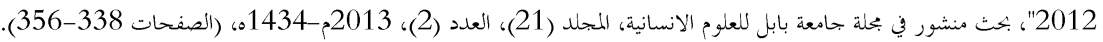

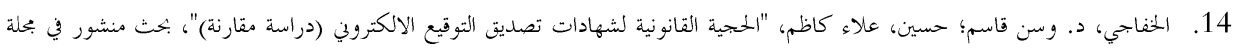

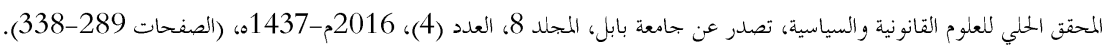

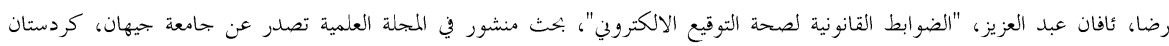

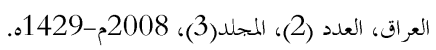

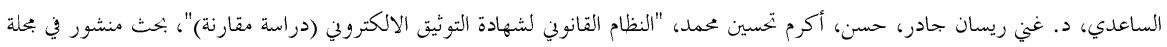

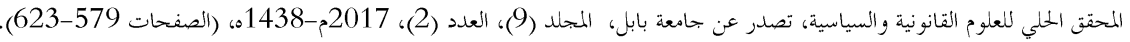


الياسري، صابرين جواد كاظم عباس، "الاطار القانوبي للوكالة بالخصومة (دراسة المقارنة)"، بحث منشور في بجلة الكوفة للعلوم القانونية

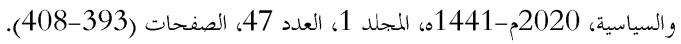

صالح، سارة مهند محمد؛ سعيد د. أكرم فاضل، "تمييز نظام التسجيل العيني عما يشتبه به من المفاهيم القانونية"، بحث منشور في بحلة كلية .18

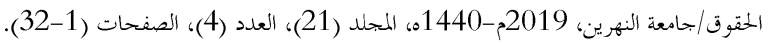

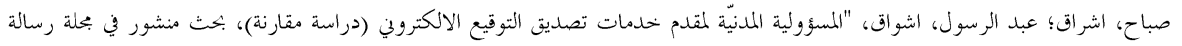
الحقوق، تصدر عن كلية القانون جامعة كربلاء، المجلد (9)، العدد (2)، 2017م-238 (2438ه، (الصفحات 308-332).

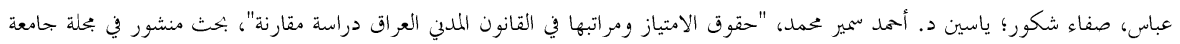

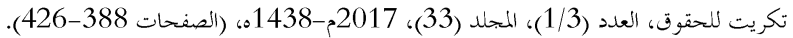
عبد الجليل، مصطفى ماجد، "الآثار القانونية لإيداع الدين بحث مقارن بالشريعة الإسلامية"، بحث منشور في بحلة رسالة الحقوق، 2011مجـ

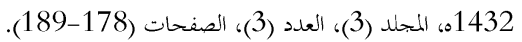
عبد، قحطان هادي، "حق الموصي في التصرف في الوصية بعد إنشائها وأثره في الفقه الإسلامي والقانون"، بحث منشور في بحلة جامعة تكريت .22

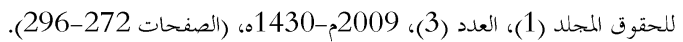
لطيف، د. زينة قدرة؛ عيال، د. عبد الله تركي، "أثر الشكلية العنية غير المباشرة على نفاذ العقد"، بحث منشور في بجلة كلية القانون للعلوم

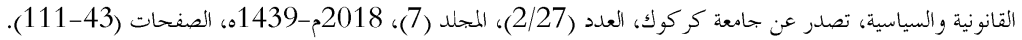

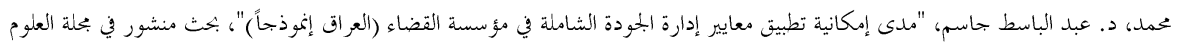

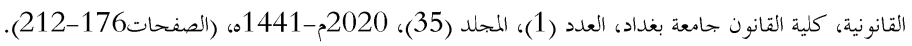

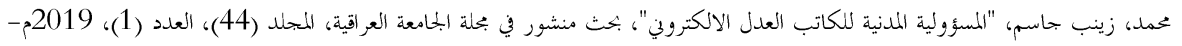
1440ه، الصفحات (455-455) زينبs) محمد، محمد رافع يونس، "أر كان الوقف وشروطه دراسة مقارنة في الفقه الإسلامي والقوانين العربية"، بحث منشور في بحلة الرافدين للحقوق، .26

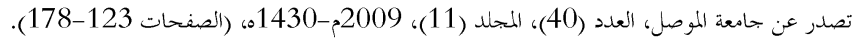
مقدم، زيد حمزة، "النظام الثانولي للتوثيق الالكتروبي دراسة مقارنة"، بحث منشور في بحلة الشريعة والقانون والدراسات الاسلامية، تصدر عن .27

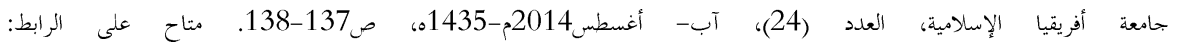
http://dspace.iua.edu.sd/handle/123456789/336

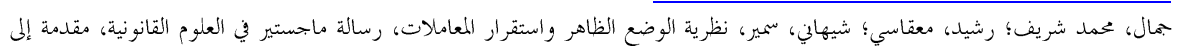

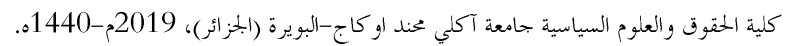

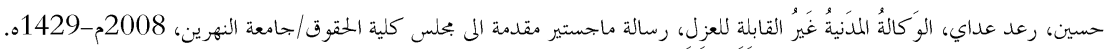

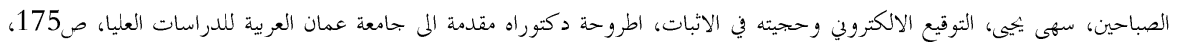
.30

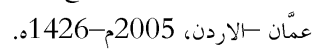

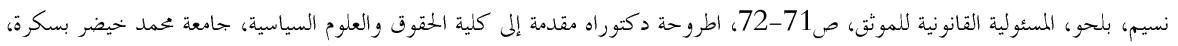
البزائر، 2015 20156 1436. وفاء، بو عصيدة، نطاق تطبيق القاعدة القانونية، رسالة ماجستير مقدمة إلى قسم الحقوق في كلية الحقوق والعلوم السياسية بجامعة مولود .32

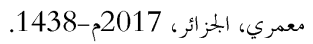
محمد، د. عبد الباسط جاسم، (المفيد في شرح القانون المدني العراقي/ الجزءء الأول مصادر الالتزام)، محاضرات القيت على طلبة المرحلة الثانية في

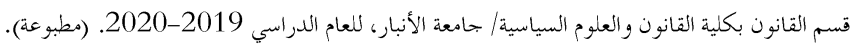
محمد، د. عبد الباسط جاسم، (المختصر المفيد في شرح أحكام المرافعات والإجراءات المدنية)، محاضرات ألقيت على طلبة المرحلة الرابعة في كلية

القانون والعلوم السياسية-قسم القانون/ جامعة الأنبار للعام الدراسي 2018-2019، (ساعدت جامعة الأنبار على طباعتها، والنسخة

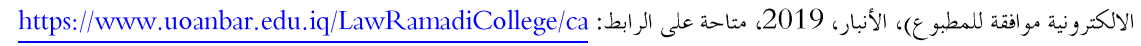

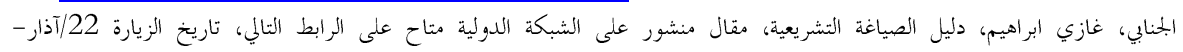
https://www.iasj.net/iasj?func=fulltext\&aId=65939:2020/ مارس 36. كاظم عبد جاسم الزيدي (قاض)، المسئولية القانونيّة للشخصيات المعنوية في القانون العراقي، مقال منشور في صحيفة الصباح العراقية، بعددها

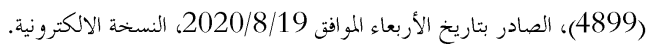




$$
\begin{aligned}
& \text { 37. ق قانون كتاب العدول العراقي رقم (23) لسنة } 1998 .
\end{aligned}
$$

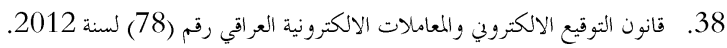

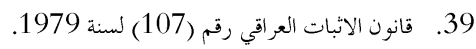

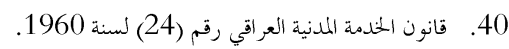

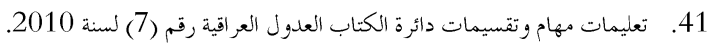

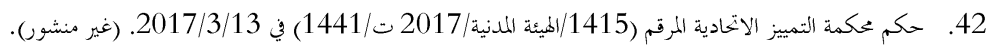

$$
\begin{aligned}
& \text { 43. حكم محكمة التمبيز الاتحادية المرقم (32/37 وصية/ } 2010 \text { في 2010/8/29). }
\end{aligned}
$$

(1) محمد، د. عبد الباسط جاسم، "مدى إمكانية تطبيق معايير إدارة الجودة الشاملة في مؤسسة القضاء (العراق إنموذجاً)"، بحث منشور في بحلة العلوم

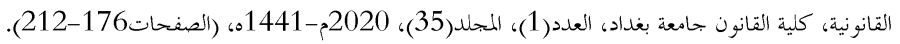

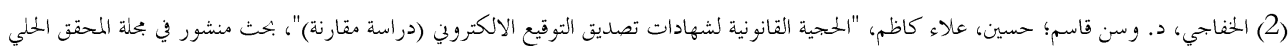

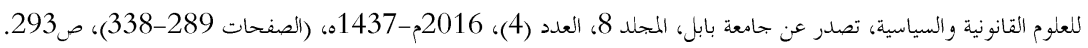

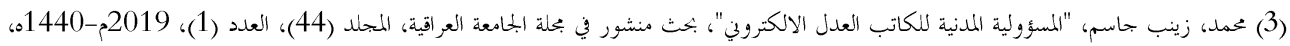

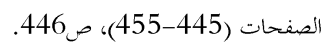

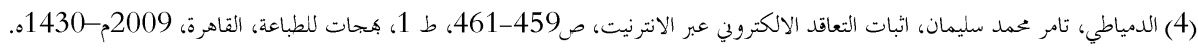

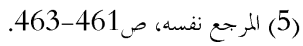

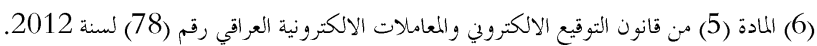
(7) رقم (23) لسنة 1998 في المادتين (1، 11، (11).

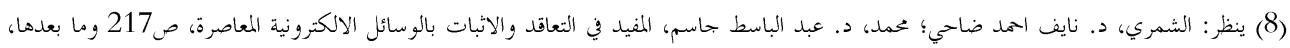

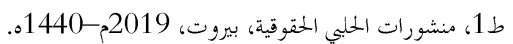
(9) حكم مكمة التمييز الاتحادية المرقم (370/وصية/ 2010 في 2010/8/29). منشور على موقع بحلس القضاء الأعلى، متاح على الرابط: /https://www.hjc.iq/qview.1370 (10) ويعرفه بعض الكتاب بأنه: (شخص عهلت اليه وظيفة عامة لقاء راتب شهري من الدولة). التميمي، فراس سامي حميد الملا جواد، الكاتب بالب بالعدل

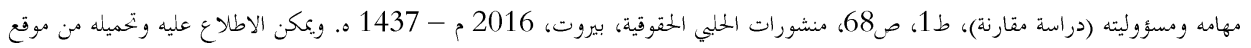

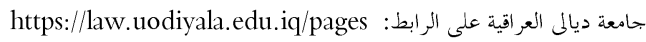

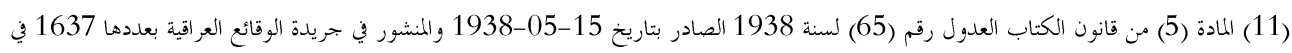

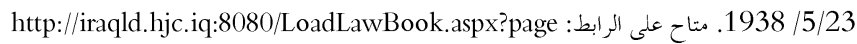
(12) المادة (1/رابع عشر) من قانون التوقيع الالكتروبي والمعاملات الالكترونية العراقي رقم (78 (78) لسنة 2012.

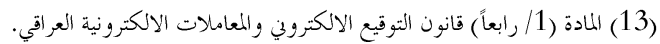

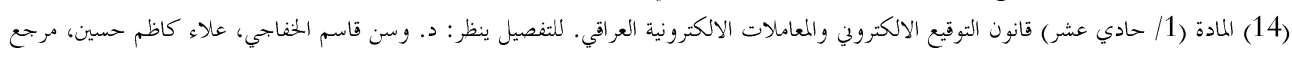
سابق، ص305. (15) المادة (1/ ثاني عشر) قانون التوقيع الالكتروبي والمعاماتات الالكترونية العراقي.

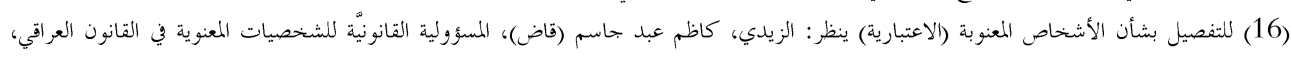

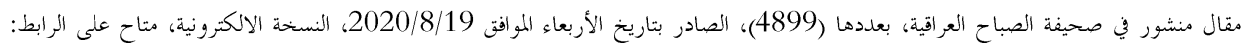
https://alsabaah.iq/

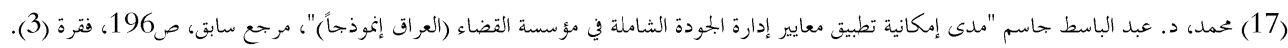

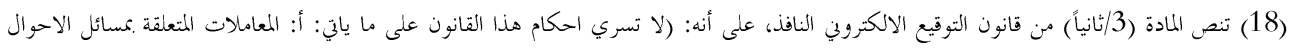

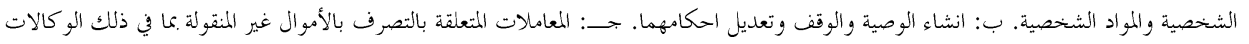


المتعلقة ها وسندات ملكيتها وانشاء الحقوق العينية عليها باستئناء عقود الايبار الخاصة هذه الاموال. د: المعاملات التي رسم لها القانون شكلية معينة. هـ :اجراءات المحاكم والاعلانات القضائية والاعلانات بالحضور واوامر التفتيش واوامر القبض والاحكام القضائية. و: أي مستند يتطلب القانون توثيقه

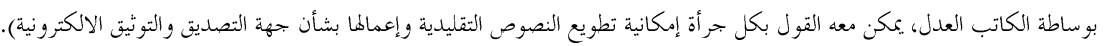

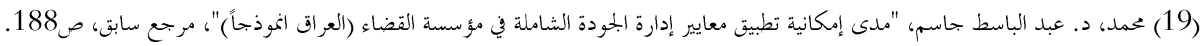

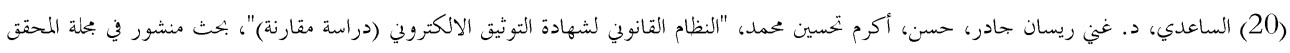

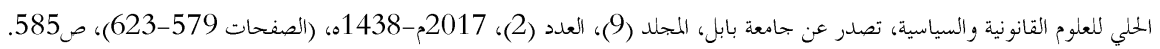
(21) الشروط العامة للتعيين هي الشروط المحددة بموجب قانون الخدمة المدنية العراقي رقم (24) لسنة 1960 المعدل. التميمي، فراس سامي حميد الملا جواد، مرجع سابق، ص101. (22) رقم (23) لسنة 1998 في المادة (6) منه. (23) يلاحظ أنٌ لوزير العدل صلاحية تعيين المعاون القضائي الممنوح صلاحية الكاتب العدل، كاتبا بالعدل إن مضت على منحه هذه الصلاحية مدة لا تقل

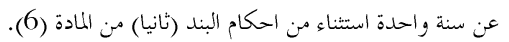
(24) المادة (7) من قانون الكتاب العدول العراقي.

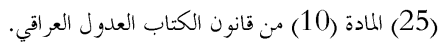

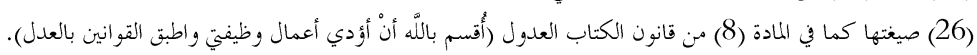
(27) المادة (8/خامسا) من قانون التوقيع الالكتروبي العراقي. (28) المادة (8/ سادسا) قانون التوقيع الالكتروبن العراقي.

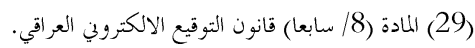

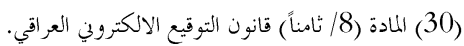

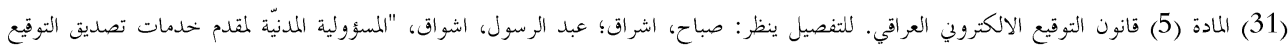

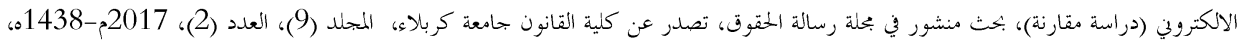

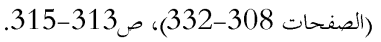

$$
\begin{aligned}
& \text { (32) المادة (7) قانون التوقيع الالكتروبي العراقي. }
\end{aligned}
$$

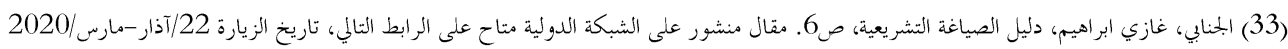
https://www.iasj.net/iasj?func=fulltext\&aId=65939: الساعة 10.00 ليالً:

$$
\text { (34) التميمي، فراس سامي حميد الملا جواد، مرجع سابق، ص63. }
$$

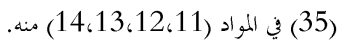

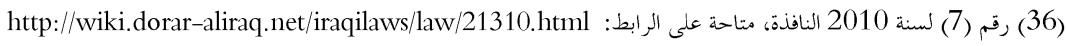
(37) هي الشؤون القانونية، الشؤون الإدارية، الشؤون المالية، التخطيط والاحصاء، وشعبة الرقابة والتدقيق الداخلي ينظر: نص المادة (2) من تعليمات مهام

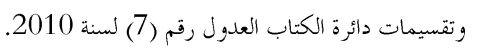

(38) مثل التصرفات الواردة على العقار في التشريع العراقي استناداً للمادة (2/3) من قانون التسجيل العقاري رقم (43) لسنة 1971 1971، التي تنص على أنه:

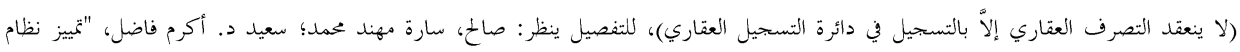

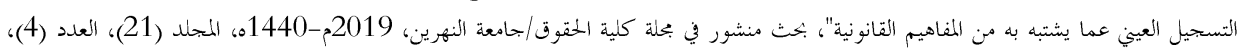

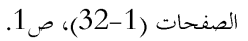

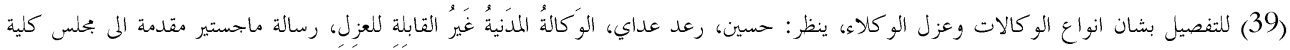

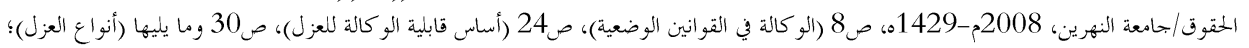

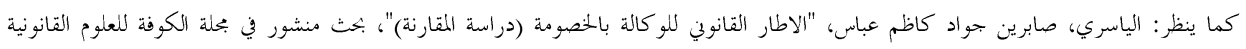

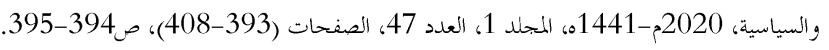

(40) تنص المادة (11/ خامساً) من قانون الكتاب العدول رقم (33) لسنة 1998 على أنْ يمارس الكاتب العدل ما يأتي: (المصادقة على المقدرة المالية

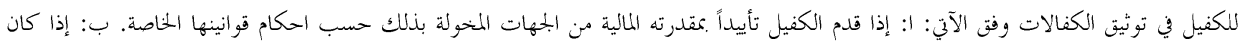


الكفيل من العاملين في دوائر الدولة أو متقاعداً بعد التأييد من مرجعه وتتحدد الكفالة بمبلغ لا يتجاوز بحموع ما يتقاضاه من رواتب وخخصصات ثابتة لمدة سنة. ج: إذا قدم الكفيل كفالة عينية أو كفالة مصرفية).

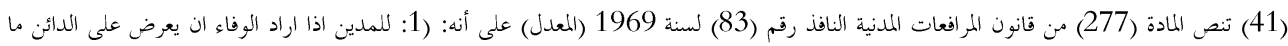

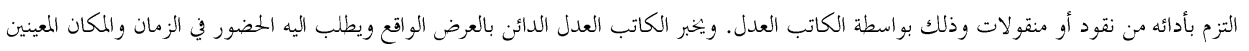

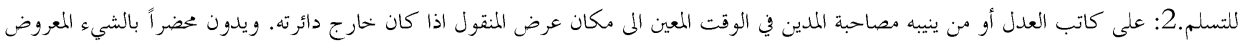

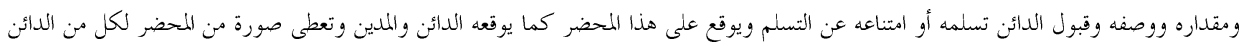
والمدين ويتمظ الكاتب العدل بالأصل). (42) للتفصيل بشأن مفهوم وإجراءات وآثار العرض والايداع: محمد، د. عبد الباسط جاسم، المختصر المفيد في شرح أحكام المرافعات والإجراءات المدنية، الماتية

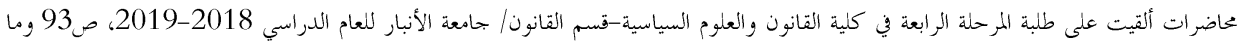

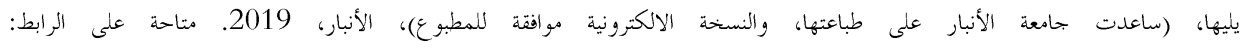
الإسلة https://www.uoanbar.edu.iq/LawRamadiCollege/ca

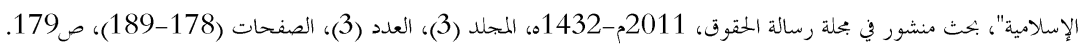

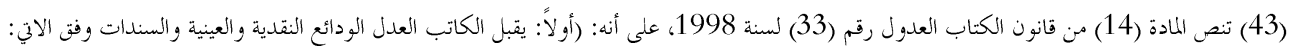

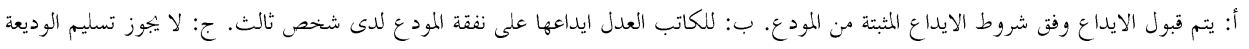

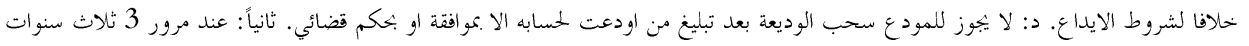

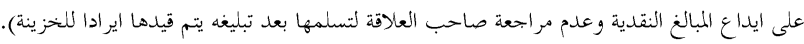

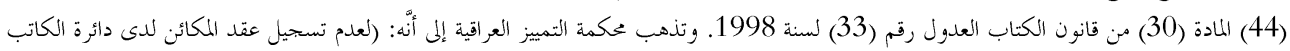

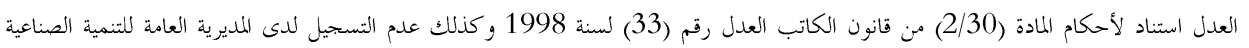

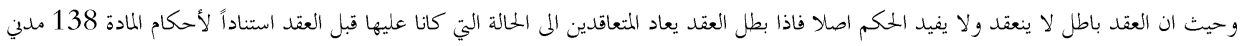

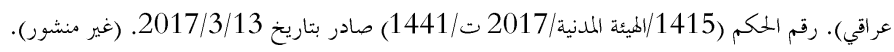

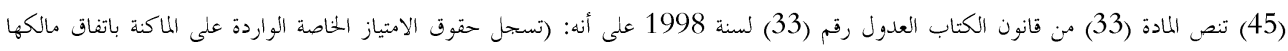

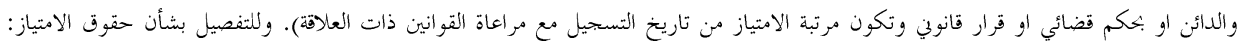

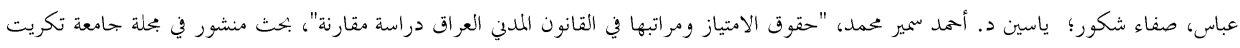

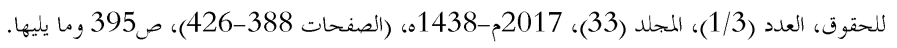
(46) المادة (3) قانون التوقيع الالكتروبن العراقي.

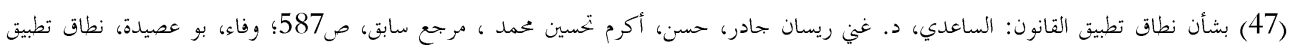

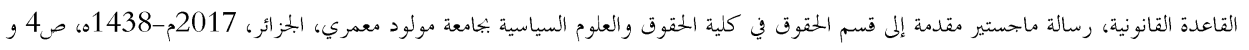

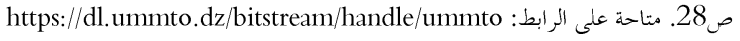

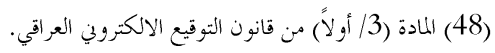

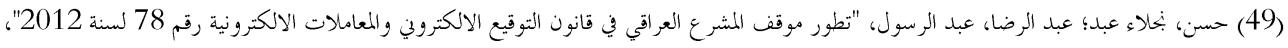

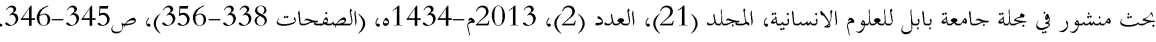

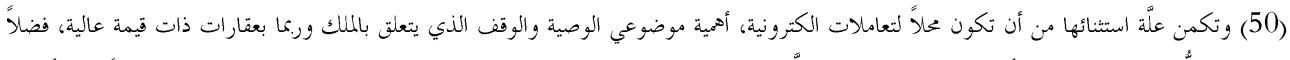

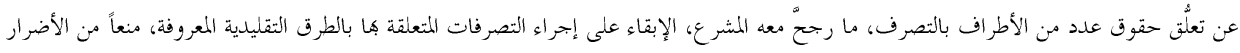

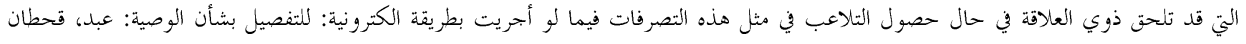

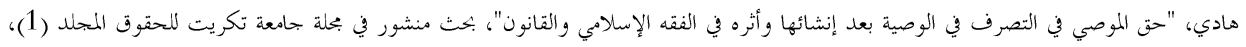

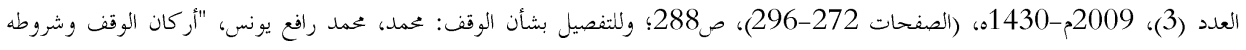

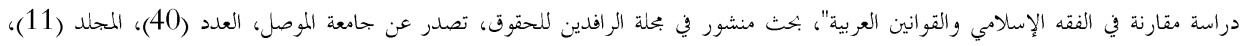

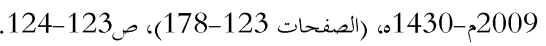




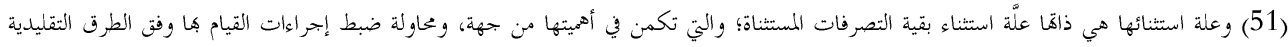

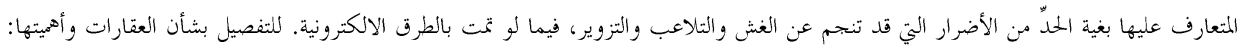

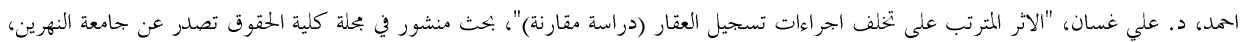

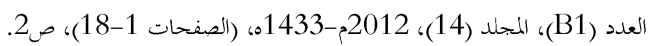

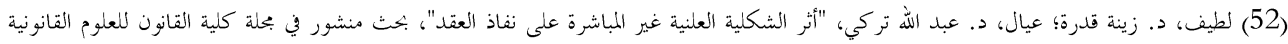

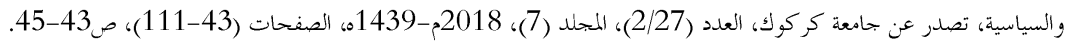

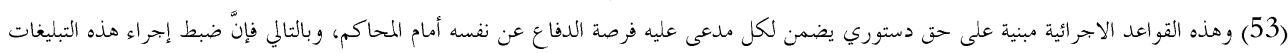

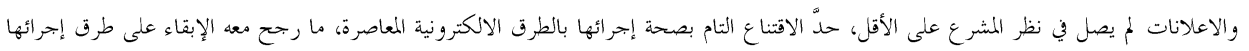

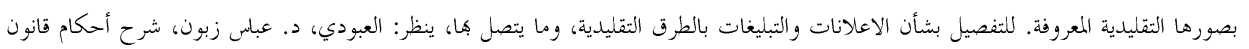

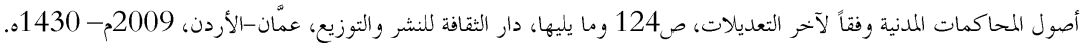

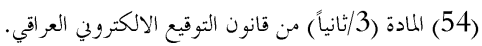

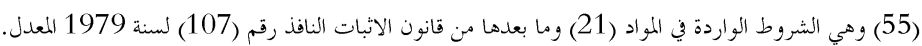

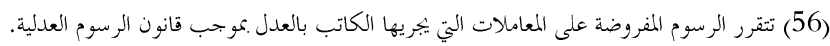

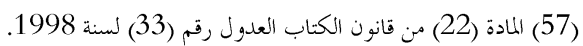

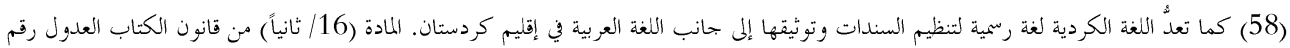

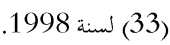
(59) المادة (16 (16 ثالثاً) من قانون الكتاب العدول رقم (33) (33) لسنة 1998.

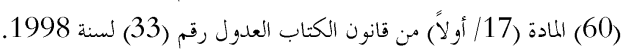

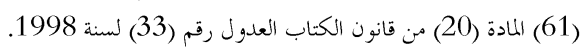

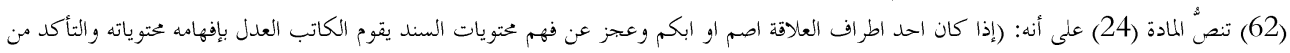

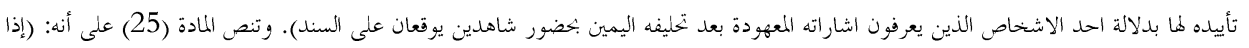

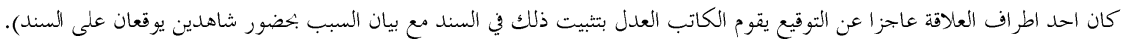

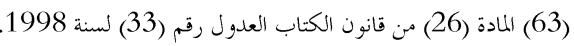

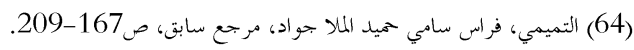

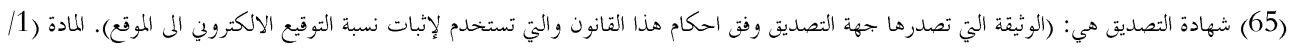

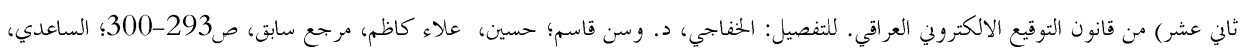

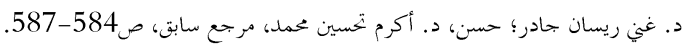
(66) المادة (1/ حادي عشر) من قانون التوقيع الالكتروفي العراقي.

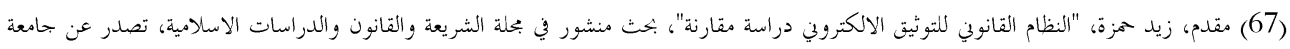

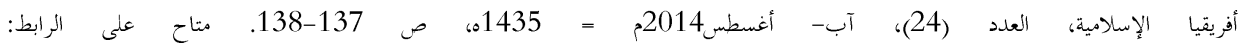
http://dspace.iua.edu.sd/handle/123456789/336

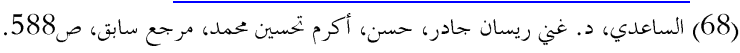

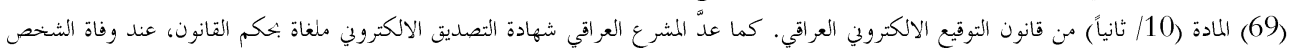

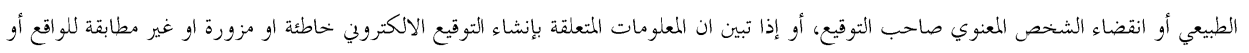

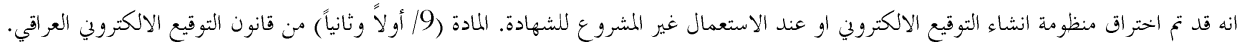

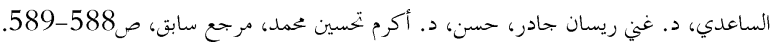

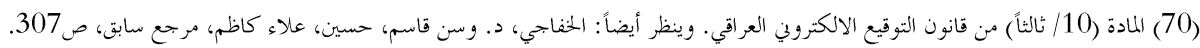

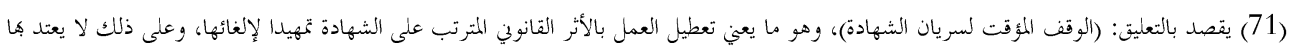

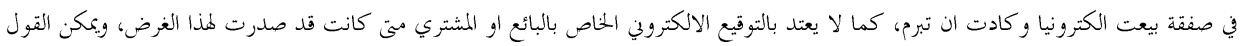


اجمالا ان تعليق العمل بالشهادة يجعلها-بصفة مؤقتة- كأن لم تكن، وذلك تمهيدا لإلغائها او استئناف سريافا متى ثبت عدم صحة السبب الذي علقت

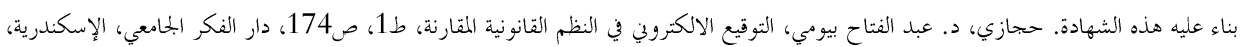
2005 201426ه (72) المادة (11/ أولاً وثانياً/أ) من قانون التوقيع الالكتروبي العراقي.

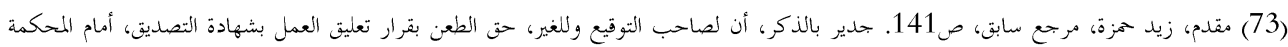

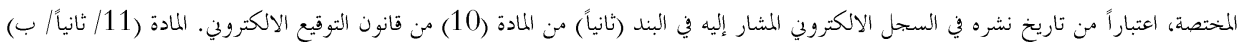
قانون التوقيع الالكتروبي العراقي.

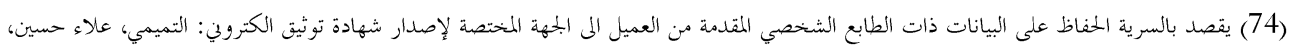

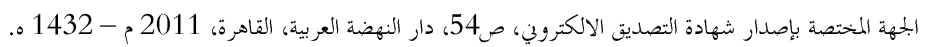

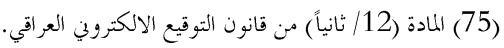

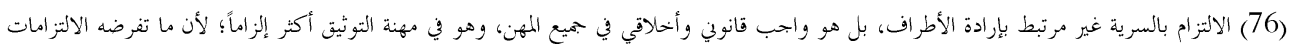

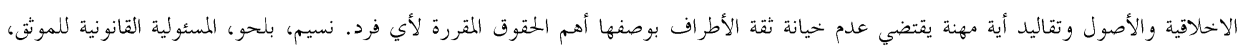

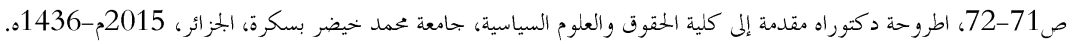
(77) المادة (12/ أولاً) من قانون التوقيع الالكتروبن العراقي.

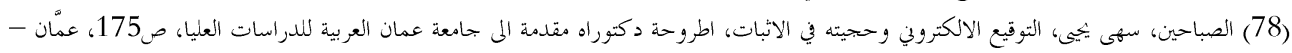

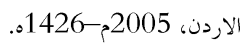

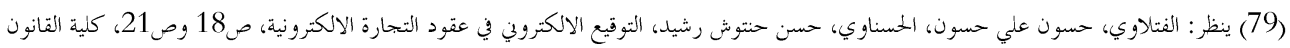

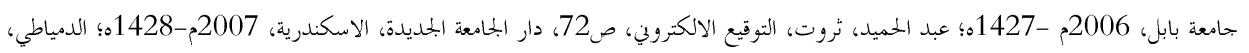

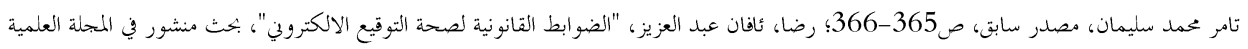

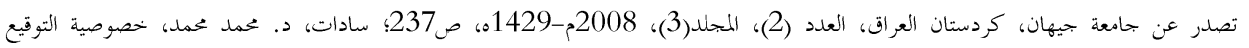

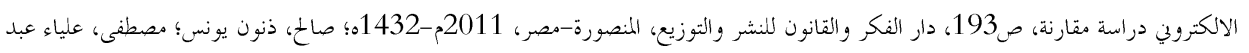
الرحمن، مصدر سابق، ص 125.

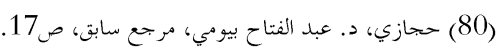

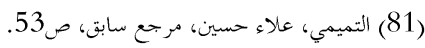

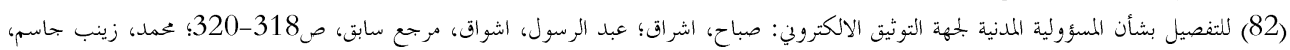
مرجع سابق، ص450 وما يليها.

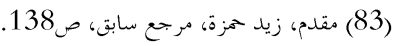
(84) جمال، محمد شريف؛ رشيد، معقاسي؛ شيهاني، سمير، نظرية الوضع الظاهر واستقرار المعاملات، رسالة ماجستير في العلوم القانونية، مقدمة إلى كلية

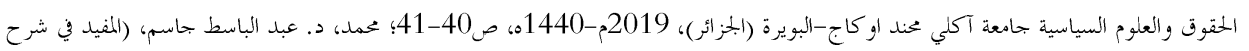

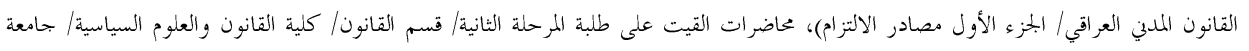

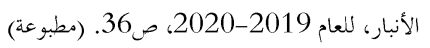

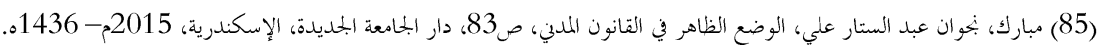

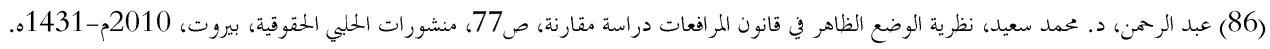

